\title{
A methodology for optimisation of solar dish-Stirling systems size, based on the local frequency distribution of direct normal irradiance
}

\author{
A. Buscemi, S. Guarino, G. Ciulla, V. Lo Brano \\ Department of Engineering \\ University of Palermo, Italy \\ e-mail: alessandro.buscemi@unipa.it, stefania.guarino@unipa.it, giuseppina.ciulla@unipa.it, \\ valerio.lobrano@unipa.it
}

\begin{abstract}
In geographical areas where direct solar irradiation levels are relatively high, concentrated solar energy systems are one of the most promising green energy technologies. Dish-Stirling systems are those that achieve the highest levels of solar-to-electric conversion efficiency, and yet they are still among the least common commercially available technologies. This paper focuses on a strategy aimed at promoting greater diffusion of dish-Stirling systems, which involves optimizing the size of the collector aperture area based on the hourly frequency distributions of beam irradiance and defining a new incentive scheme with a feed-in tariff that is variable with the installed costs of the technology. To this purpose, a new numerical model was defined and calibrated on the experimental data collected for an existing dish-Stirling plant located in Palermo (Italy). Hourly-based simulations were carried out to assess the energy performance of 6 different system configurations located on 7 sites in the central Mediterranean area using two different solar databases: Meteonorm and PVGIS. A new simplified calculation approach was also developed to simulate the dish-Stirling energy production from the hourly frequency histograms of the beam irradiance. The results reveal that an optimised dish-Stirling system can produce $70-87 \mathrm{MWh}_{\mathrm{e}} /$ year in locations with direct irradiation varying between $2000-2500 \mathrm{kWh} /\left(\mathrm{m}^{2} \cdot\right.$ year $)$. The proposed incentive scheme would guarantee a payback time for investment in this technology of about ten years and the effect of economies of scale could lead, over the years, to a levelized cost of energy similar to that of other concentrating power systems.
\end{abstract}

\section{HIGHLIGHTS}

- DNI hourly frequency distribution is analysed in 7 Mediterranean locations.

- Influence of DNI peak values on electricity production are investigated.

- Effects of redesigned and optimised aperture area of the collector are analysed.

- A new procedure using DNI frequency histograms to forecast energy production is presented.

Preprint version; Please cite this paper as: Buscemi, A., Guarino, S., Ciulla, G., \& Lo Brano, V. (2021). A methodology for optimisation of solar dish-Stirling systems size, based on the local frequency distribution of direct normal irradiance. Applied Energy, 303, 117681. 
- Solar data from PVGIS, an alternative to Meteonorm, was used to optimise reflector size.

\section{KEYWORDS}

dish-Stirling, Concentrating Solar Power, numerical models, LCOE, solar datasets, incentive policies

\section{INTRODUCTION}

Carbon dioxide $\left(\mathrm{CO}_{2}\right)$ emissions contribute to more than half of the greenhouse gases (GHG) in the atmosphere and have a strong impact on climate change [1]. However, in recent years, the increasing use of renewable energy sources, such as solar and wind power, and the use of natural gas as opposed to coal for power generation, have allowed the slowing of the growing trend in power generation $\mathrm{CO}_{2}$ emissions [2]. Of the renewable technologies currently available, systems that use solar energy to generate electricity, such as photovoltaic (PV) and concentrating solar power (CSP) systems, are rapidly growing [3], even in specific context such as on a small island with a segregated grid [4]. Although almost 98\% of the solar systems annually installed are PV plants, CSP systems are considered to have significant potential in contributing to future electricity production [5]. CSP systems use a collector consisting of mirrors or lenses to concentrate the direct normal irradiance (DNI) [6] on a receiver obtaining high-temperature thermal energy, which is eventually converted into mechanical and electrical energy [7]. There are four different types of CSP systems: parabolic trough collectors, linear Fresnel reflectors, solar power towers, and parabolic dishes [8].

Data issued by the National Renewable Energy Laboratory (NREL) shows that the CSP plants currently operating or under development all around the world have a total peak power of about 10 GW [9]. Around $62 \%$ of these plants are parabolic trough systems, $34 \%$ are solar towers and about $4 \%$ are Fresnel systems. Approximately $6 \mathrm{GW}$, equally distributed between the parabolic trough and solar tower systems, refer to plants equipped with thermal storage having a capacity of more than 8 hours. This data is consistent with the fact that parabolic trough collectors have reached higher commercial maturity earlier [3] and that more recently the number of solar tower systems is growing considerably [9]. Moreover, a comparison in terms of levelized costs of electricity (LCOE) [10] of these two technologies shows that solar towers are currently more economically viable (LCOE $=0.09$ $€ / \mathrm{kWh})$ than parabolic trough collectors $(\mathrm{LCOE}=0.21 € / \mathrm{kWh})[11]$. Interestingly, dish collector systems, usually equipped with Stirling engines [12], are almost completely absent from the aforementioned CSP power generation scenarios, despite this technology holding the record for solar-

Preprint version; Please cite this paper as: Buscemi, A., Guarino, S., Ciulla, G., \& Lo Brano, V. (2021). A methodology for optimisation of solar dish-Stirling systems size, based on the local frequency distribution of direct normal irradiance. Applied Energy, 303, 117681. 
to-electric peak conversion efficiency [13]. In most cases, in fact, dish-Stirling concentrators are still part of pilot projects [3]. These projects have demonstrated that dish-Stirling concentrators are characterised by a high level of modularity [14] and present a relatively low land occupancy compared to the other CSP systems [13]. Owing to these special features, dish-Stirling systems have been used in several applications, including [15]: heat and power micro-cogeneration [16], heating, ventilation and air conditioning of residential [17] and tertiary buildings [18], power generation in remote rural areas [19], potable water production [20], water pumping [21] and hybridization with other renewable energy sources [22]. In [23] a new hybrid system was proposed, where solar energy collected by a dish-Stirling system can be indirectly used in a high-efficiency power engine in form of syngas to increase electricity production.

The low commercial penetration of dish-Stirling systems in the renewable solar power generation market can be partially attributed to the fact that these systems are more difficult to combine with thermal energy storage [24] with respect to the other CSP systems. Furthermore, the presence of a thermal storage system would reduce the cost of electricity produced thanks to the continuity of operation during night time hours [25]. However, as shown by the analysis of the installed plant data [9], dish-Stirling concentrators are not widespread among the CSP plants without energy storage either (about $40 \%$ of the total installed plants). The fact that Stirling engines are not produced on a large scale and have a relatively high initial cost [26] is certainly another strong barrier to the commercial penetration of this technology [8]. In around 2001, an interesting concept to increase the profitability of these systems [27] was proposed with the Schlaich Bergermann und Partner (SBP) EuroDish collector installed in Spain for demonstration use [28]. This pilot system, with a peak output power of $10 \mathrm{~kW}_{\mathrm{e}}$ corresponding to a DNI level of $800 \mathrm{~W} / \mathrm{m}^{2}$, was optimised as a function of the DNI hourly frequency distribution typical of the installation location. This technological improvement was realised by both enlarging the reflector size and using a fan cooler for the dissipation of the surplus of thermal energy absorbed by the collector cavity receiver during the few hours of the year when the DNI level exceeds the value of $800 \mathrm{~W} / \mathrm{m}^{2}$ [29]. Nonetheless, these technological developments have not been sufficient to increase the diffusion of dish-Stirling systems in the last two decades. Appropriate incentive policies [30] could encourage greater commercial penetration of CSP systems $[31,32]$ by activating economies of scale that can reduce the initial costs of this promising renewable technology [33] and speed the dish-Stirling technology toward grid parity [34]. However, a correct and reliable assessment of the energy production of these systems is a necessary step to design a dedicated specific incentive scheme. Conveniently, numerical models

Preprint version; Please cite this paper as: Buscemi, A., Guarino, S., Ciulla, G., \& Lo Brano, V. (2021). A methodology for optimisation of solar dish-Stirling systems size, based on the local frequency distribution of direct normal irradiance. Applied Energy, 303, 117681. 
calibrated on the operating data of existing dish-Stirling plants [35] can be used for this purpose [36]. Usually, these models calculate the electric output power of dish-Stirling systems as a function of the DNI, of the external air temperature and of the soiling level of the collector mirrors [37]. Of these, the solar beam radiation which characterizes each plant installation site [38] is the factor that most influences both the system sizing [39] and the prediction of its energy output [40]. Most of the popular models used for DNI assessment are based on the estimation of both the global horizontal irradiation and the diffuse fraction of the solar radiation, the latter often determined from the clearness index [41]. Alternatively, using different models it is possible to estimate the beam irradiance directly from satellite images [42]. Through these different approaches it is then possible to stochastically generate hourly synthetic DNI time series [43] that can be used to perform hourly simulations useful for calculating the annual energy produced by dish-Stirling systems.

A novel strategy to encourage greater commercial diffusion of dish-Stirling systems is outlined and proposed in this paper. This strategy combines the optimization of the collector size to the solar radiation conditions of the installation site with the definition of a new incentive scheme. Concerning the optimization of the collector size, an approach similar to that proposed for Euro Dish systems was followed in this work. Since no relevant information was found in the literature for this case, a new numerical approach was defined to assess the energy production of dish-Stirling system equipped with a fan cooler installed inside the receiver. To this aim, a recent numerical dish-Stirling simulation model [42] was expanded by introducing the term representing the input solar energy surplus to be dissipated into the energy balance of the receiver. This quantity was properly expressed as a function of both the nominal peak thermal input power of the Stirling engine and the current DNI levels. The proposed model allows the optimization of the concentrator mirror size considering both the Stirling engine characteristics and typical solar radiation conditions of the plant location.

A new simplified calculation algorithm allowing the energy production assessment of dishStirling systems using the frequency histogram of 1-hour DNI series as input is also proposed. This method could present a useful application in the optimization of dish-Stirling systems for macro geographical regions for which it would be possible to elaborate statistically a single typical average frequency histogram of a 1-hour DNI series.

Finally, as a fundamental part of the outlined strategy defined within this work, a novel incentive scheme, with a time-varying feed-in tariff is proposed for dish-Stirling systems. This scheme is based both on a realistic hypothesis of a reduction in the plant installation cost over time,

Preprint version; Please cite this paper as: Buscemi, A., Guarino, S., Ciulla, G., \& Lo Brano, V. (2021). A methodology for optimisation of solar dish-Stirling systems size, based on the local frequency distribution of direct normal irradiance. Applied Energy, 303, 117681. 
based on the analysis of historical data from CSP technologies and on the assumption of a constant payback time values for plants built during the incentivised period. This proposed incentive mechanism aims to find a trade-off between the interests of CSP investors and those of the local governments providing the incentive. Thus, the proposed incentive scheme can be seen as an interesting contribution to national energy policies for this type of renewable technology mainly because this approach can be generalised for different geographical locations.

The proposed energo-economic strategy was tested for dish-Stirling systems located in the central Mediterranean area. To this aim, 6 different plant configurations hypothetically installed in 7 different locations were considered. For each location two different input solar data sets were used as input (Meteonorm and PVGIS - Photovoltaic Geographical Information System). The results of these analyses made it possible to evaluate both the LCOE and the optimised feed-in tariff function for this geographical location.

The paper is organised as follows: Section 2 analysed presents: the new dish-Stirling energy model and algorithms, the processing of the two input solar datasets, the LCOE, and the description of the incentive scheme hypothesis. Section 3 describes all the analysed case studies. Section 4 reveals and discusses the results. Lastly, Section 5 draws conclusions from the present research.

\section{METHODS}

In this section the physical mathematical model used to carry out the energy analyses of the different studied dish-Stirling concentrator configurations is presented. For each location selected in this study, two different solar databases were chosen in order to extract the hourly series of the numerical model input variables. Afterwards, two different calculation approaches were defined to carry out the evaluation of the electric energy outputs of the 42 studied cases. Finally, the numerical results of these energy analyses were used as a basis both to analyze the LCOE and to define a new scheme of incentives dedicated to dish-Stirling plants.

\subsection{The energy balance of the dish-Stirling collector}

Adopting an approach recently proposed in the literature [35], the net electric output power $\dot{E}_{n}[\mathrm{~W}]$ produced by a dish-Stirling solar collector can be calculated as a function of the variations of the solar beam irradiance $I_{b}\left[\mathrm{~W} / \mathrm{m}^{2}\right]$ and the air temperature $T_{\text {air }}\left[{ }^{\circ} \mathrm{C}\right]$ by the following relation:

$$
\dot{E}_{n}=\left(\eta_{e} \cdot \eta_{o} \cdot \eta_{c l e}^{a v e} \cdot a_{1} \cdot A_{n} \cdot R_{T}\right) \cdot I_{b}-\left[\eta_{e} \cdot\left(a_{1} \cdot \dot{Q}_{r, \text { out }}+a_{2}\right) \cdot R_{T}+\dot{E}_{p}^{a v e}\right]
$$

Preprint version; Please cite this paper as: Buscemi, A., Guarino, S., Ciulla, G., \& Lo Brano, V. (2021). A methodology for optimisation of solar dish-Stirling systems size, based on the local frequency distribution of direct normal irradiance. Applied Energy, 303, 117681. 
where:

- $\quad \eta_{c l e}^{\text {ave }}[-]$ is the average cleanliness index of the collector mirrors

- $\quad \eta_{e}[-]$ is the electric efficiency of the alternator

- $\quad \eta_{o}[-]$ is the optical efficiency of the system

- $\quad a_{1}[-], a_{2}[\mathrm{~W}]$ are two fitting parameters of the Stirling engine mechanical efficiency curve

- $A_{n}\left[\mathrm{~m}^{2}\right]$ is the net effective aperture area of the reflector

- $\quad \dot{E}_{p}^{\text {ave }}[\mathrm{W}]$ is the average value of the parasitic plant consumption

Two other terms are present in Eq. 1, the first of which represents the heat loss from the receiver:

$$
\dot{Q}_{r, \text { out }}=A_{r} \cdot\left\{h_{r} \cdot\left(T_{r}^{a v e}-T_{\text {air }}\right)+\sigma \cdot \varepsilon_{r} \cdot\left[\left(T_{r}^{a v e}+273.15\right)^{4}-\left(T_{s k y}+273.15\right)^{4}\right]\right\}
$$

where:

- $\quad A_{r}\left[\mathrm{~m}^{2}\right]$ is the receiver aperture area

- $\quad h_{r}\left[\mathrm{~W} /\left(\mathrm{m}^{2} \cdot \mathrm{K}\right)\right]$ is the receiver convective coefficient

- $\quad T_{r}^{\text {ave }}\left[{ }^{\circ} \mathrm{C}\right]$ is the average receiver temperature

- $\quad \sigma=5.67 \cdot 10-8\left[\mathrm{~W} /\left(\mathrm{m}^{2} \cdot \mathrm{K}^{4}\right)\right]$ is the Stefan-Boltzmann constant

- $\quad \varepsilon_{r}[-]$ is the effective emissivity of the receiver

and $T_{s k y}\left[{ }^{\circ} \mathrm{C}\right]$ is the apparent sky temperature that can be calculated using the following empirical expression [44]:

$$
T_{\text {sky }}=0.0552 \cdot\left(T_{\text {air }}+273.15\right)^{1.5}-273.15
$$

The second term appearing in Eq. 1 is a temperature correction factor, defined as:

$$
R_{T}=\left(\frac{T_{0}+273.15}{T_{a i r}+273.15}\right)
$$

where $T_{0}\left[{ }^{\circ} \mathrm{C}\right]$ is a reference temperature. This term derivates from the empirical expression used to model the mechanical output power $\dot{W}_{S}[\mathrm{~W}]$ of the Stirling engine as a function of its thermal input power $\dot{Q}_{S, i n}[\mathrm{~W}][35]$ :

$$
\dot{W}_{S}=\left(a_{1} \cdot \dot{Q}_{S, i n}-a_{2}\right) \cdot R_{T}
$$

Preprint version; Please cite this paper as: Buscemi, A., Guarino, S., Ciulla, G., \& Lo Brano, V. (2021). A methodology for optimisation of solar dish-Stirling systems size, based on the local frequency distribution of direct normal irradiance. Applied Energy, 303, 117681. 
The above model, was developed [35] by introducing a simplified expression of the Stirling engine part load efficiency into the set of equations describing the energy balance of the system and was calibrated using data from plant operation of a real dish-Stirling plant. With this approach it is possible to perform optimization analyses of dish-Stirling components taking into account the main parameters governing the efficiency of the system.

\subsection{A model considering surplus of energy input on the receiver}

This thermal power $\dot{Q}_{S, i n}$, delivered to the Stirling engine, can be calculated from the energy balance of the receiver as:

$$
\dot{Q}_{\mathrm{S}, i n}=\left(\eta_{o} \cdot \eta_{c l e} \cdot A_{n}\right) \cdot I_{b}-\left(\dot{Q}_{r, \text { out }}+\dot{Q}_{r e j}\right)
$$

where the newly defined term $\dot{Q}_{r e j}$ [W] represents the heat power that can be rejected from the receiver by a hypothetical cooling fan. This latter term was added to the energy balance since some dish-Stirling models, such as the SPB EuroDish system [29], allow the receiver temperature to be controlled by a cooling fan dissipating the surplus of solar energy input. This device is activated whenever the thermal input power to the engine is higher than an upper limit value $\dot{Q}_{S, \text { in }}^{\max }$ which depends on the engine characteristics. This limit value is reached when $I_{b}$ exceeds a maximum value that can be calculated by the following equation:

$$
I_{b}^{\max }=\frac{\left(\dot{Q}_{S, \text { in }}^{\max }+\dot{Q}_{r, \text { out }}\right)}{\left(\eta_{o} \cdot \eta_{c l e} \cdot A_{n}\right)}
$$

that is deduced from Eq. 6, by imposing $\dot{Q}_{r e j}$ equal to zero. It is noteworthy that $I_{b}^{\max }$ depends not only on the reflector and engine characteristics, but also on the ambient temperature $T_{\text {air }}$ (from the dependence of $I_{b}^{\max }$ from $\left.\dot{Q}_{r, \text { out }}\right)$. Thus, the thermal power that can be dissipated by the receiver fan cooler, can be calculated as a function of $I_{b}$ ad $T_{\text {air }}$, by the following relation:

$$
\dot{Q}_{r e j}=\left(\eta_{o} \cdot \eta_{c l e} \cdot A_{n}\right) \cdot I_{b}-\left(\dot{Q}_{S, \text { in }}^{\max }+\dot{Q}_{r, \text { out }}\right)
$$

which is deducted from Eq. 6 by imposing $\dot{Q}_{S, \text { in }}$ equal to its maximum value $\dot{Q}_{S, \text { in }}^{\max }$. The operation of the Stirling engine is also limited by a minimum value of thermal input energy $\dot{Q}_{S, \text { in }}^{\min }$, below which

Preprint version; Please cite this paper as: Buscemi, A., Guarino, S., Ciulla, G., \& Lo Brano, V. (2021). A methodology for optimisation of solar dish-Stirling systems size, based on the local frequency distribution of direct normal irradiance. Applied Energy, 303, 117681. 
the engine does not start. In a similar way to that described above for Eq. 7, the minimum value of beam solar irradiance useful for the system operation can be deduced from Eq. 6 as:

$$
I_{b}^{\min }=\frac{\left(\dot{Q}_{S, \text { in }}^{\min }+\dot{Q}_{r, \text { out }}\right)}{\left(\eta_{o} \cdot \eta_{c l e} \cdot A_{n}\right)}
$$

which, as previously explained, is also a function of the external temperature $T_{\text {air }}$.

The energy model described by the set of Eqs. 1-4 was used to perform the hourly-based simulations of the electric power outputs of the 42 analysed plants as a function of the changes of both the beam solar irradiance and air temperature. To this end, the real operating data of the pilot plant of Palermo University [35] was used to define the model calibration parameters which are those summarised in Tab. 1. The values of the reflector aperture area $A_{n}$ used to specialize the energy model in the 6 different collector configurations are those already listed in the previous section of this paper.

Table 1: model parameters defined for the dish-Stirling plant of Palermo

\begin{tabular}{|c|c|c|}
\hline Parameters & Value & Unit \\
\hline Receiver aperture area $A_{r}$ & 0.0314 & $\mathrm{~m}^{2}$ \\
\hline Clean mirrors optical efficiency $\eta_{o}$ & 0.85 & - \\
\hline Receiver convective coefficient $h_{r}$ & 10 & $\mathrm{~W} /\left(\mathrm{m}^{2} \cdot \mathrm{K}\right)$ \\
\hline Receiver effective emissivity $\varepsilon_{r}$ & 0.88 & - \\
\hline Parameter $a_{1}$ of Eq. 6 & 0.475 & \\
\hline Parameter $a_{2}$ of Eq. 6 & 3.319 & $\mathrm{~kW}$ \\
\hline Average Receiver temperature $T_{r}^{\text {ave }}$ & 720 & ${ }^{\circ} \mathrm{C}$ \\
\hline Reference temperature $T_{0}$ & 25 & ${ }^{\circ} \mathrm{C}$ \\
\hline Max engine thermal input power ${ }^{(*)} \dot{Q}_{S, i n}^{\max }$ & 85 & $\mathrm{~kW}$ \\
\hline Min engine thermal input power ${ }^{*}{ }^{*} \dot{Q}_{S, i n}^{\min }$ & 11 & $\mathrm{~kW}$ \\
\hline Electrical efficiency of the $C P U, \eta_{e}$ & 0.924 & - \\
\hline Average parasitic absorption $\dot{E}_{p}^{\text {ave }}$ & 1.60 & $\mathrm{~kW}$ \\
\hline Average cleanliness index $\eta_{c l e}^{\text {ave }}$ & 0.85 & - \\
\hline
\end{tabular}

Preprint version; Please cite this paper as: Buscemi, A., Guarino, S., Ciulla, G., \& Lo Brano, V. (2021). A methodology for optimisation of solar dish-Stirling systems size, based on the local frequency distribution of direct normal irradiance. Applied Energy, 303, 117681. 
Finally, it is possible to calculate the instantaneous solar-to-electric energy conversion efficiency using the equations described above as follows:

$$
\eta_{\text {sol-ele }}=\frac{\dot{E}_{n}}{I_{b} \cdot A_{n}}
$$

The annual value of the solar-to-electric efficiency, instead, can be calculated as:

$$
\bar{\eta}_{\text {sol-ele }}=\frac{E_{t}}{D N I_{e} \cdot A_{n}}
$$

where: $E_{t}$ is the annual electricity production of the dish-Stirling system and $D N I_{\mathrm{e}}\left[\mathrm{kWh} /\left(\mathrm{m}^{2} \cdot\right.\right.$ year $\left.)\right]$ is the annual effective direct solar irradiation. The latter quantity is obtained by integrating over time only the direct solar irradiance values greater then $I_{b}^{\mathrm{min}}$.

\subsection{A new simplified algorithm to assess electricity production from DNI frequency histograms}

As described in the previous subsection, the electrical output of a dish-Stirling system essentially depends on both the level of direct normal irradiance and the outdoor temperature value. In this regard, the accuracy of predicting long-term energy production of a CSP system does not exclusively depend on the reliability of the numerical model, but also on the representativity of the DNI data used as input. Unfortunately, an accurate elaboration of a DNI time series, representative of the long-term average conditions for a given location, is far from simple [45]. In this study, the input variables of the dish-Stirling model were elaborated using two different solar datasets (Meteonorm [46] and PVGIS [47]) in order to assess their influence on the numerical energy predictions. Meteonorm is a reliable source of meteorological parameters providing a typical meteorological year (TMY) for any location in the world. However, DNI values extracted from this synthetic data can differ significantly from ground measurements [48]. On the other hand, PVGIS is a European solar data information system that is used to assess energy production of photovoltaic systems. This data is based on images provided by the Meteosat East geostationary satellites [49], and, therefore, may be inaccurate on cloudy days [50]. Thus, using both the TMY generated by Meteonorm and the PVGIS solar data elaborated from 10 years of satellite measurements (2007-2016), it was possible to define two different series of hourly $I_{\mathrm{b}}$ and $T_{\text {air }}$ values for each of the 7 studied locations.

The climate data of each location was used to assess the net electrical outputs of the dish-Stirling systems using two different calculation approaches. These methods, which are summarised in the flowchart in Fig. 1, are referred to as time-based and simplified approaches respectively. According

Preprint version; Please cite this paper as: Buscemi, A., Guarino, S., Ciulla, G., \& Lo Brano, V. (2021). A methodology for optimisation of solar dish-Stirling systems size, based on the local frequency distribution of direct normal irradiance. Applied Energy, 303, 117681. 
to the first approach, the hourly series of the two metereological input variables $\left(I_{\mathrm{b}}\right.$ and $T_{\text {air }}$ ), represented by box (a) of Fig. 1, are used to directly calculate the corresponding hourly series of the net electrical output power $\left(\dot{E}_{n}\right)_{h o r}$ values by means of the electric power production model described by Eqs. 1-4 (see box (b) in Fig. 1). Thus, in the flowchart in Fig. 1 the hourly-based approach is simply described by the two boxes (a) and (b). Then in order to effectively represent the hourly input values from box (a) and the output values from box (b), hourly frequency histograms were elaborated through the binning procedure that is described in box (c) in Fig. 1. According to this data binning procedure, the range of $I_{b}$ values of the input dataset of box (a) was divided into a series of consecutive non-overlapping bins, all having the same width $\Delta I_{b}\left[\mathrm{~W} / \mathrm{m}^{2}\right]$. Thus, using both the data of box (a) and the $\left(\dot{E}_{n}\right)_{\text {hor }}$ values from box (b), the following quantities were calculated for each bin:

- $\quad n_{I_{b}}[\mathrm{~h}]$, representing the number of records falling into the bin. That is, the number of hours during which $I_{b}$ occurred with values included within the extremes of the definition of the bin;

- $\quad \bar{T}_{\text {air }}\left[{ }^{\circ} \mathrm{C}\right]$, representing the average of all the $T_{\text {air }}$ values corresponding to records having an $I_{b}$ value falling into the bin. These different values of $T_{\text {air }}$ in each bin are related to the fact that, during the year, there are hours characterised by the same level of direct normal irradiance but different air temperature values;

- $\bar{I}_{b}\left[\mathrm{~W} / \mathrm{m}^{2}\right]$, which is the mid point value of the extremes defining the bin width;

- $E_{s}\left[\mathrm{kWh} / \mathrm{m}^{2}\right]$ representing the total amount of the solar direct normal energy that can be calculated by multiplying $\bar{I}_{b}$ by $n_{I_{b}}$;

- $\left(E_{t}\right)_{h o r}[\mathrm{kWh}]$, which is the net electric output energy that is calculated by summing the hourly values of $\left(\dot{E}_{n}\right)_{h o r}$ that fall in the bin. In other words, the addends of this sum are the output values of box (b) corresponding to those $I_{b}$ values which belong to the bin.

Unlike the first approach, the simplified method (described by box (d) in Fig. 1) requires, as input data, the result values of the binning procedure of box (c). In other words, this second method allows the energy calculation using the hourly frequency distributions of direct normal irradiance (and the corresponding $\bar{T}_{\text {air }}$ values) as input. To this aim, starting from the triplets $\left(\bar{I}_{b}, \bar{T}_{a i r}, n_{I_{b}}\right)$ defined for each bin with of procedure described by box (c), it is possible to calculate the net electric output

Preprint version; Please cite this paper as: Buscemi, A., Guarino, S., Ciulla, G., \& Lo Brano, V. (2021). A methodology for optimisation of solar dish-Stirling systems size, based on the local frequency distribution of direct normal irradiance. Applied Energy, 303, 117681. 
power $\left(\dot{E}_{t}\right)_{\text {sim }}$ corresponding to each bin by means of Eqs. 1-4. Finally, for each bin, the net electric output energy $\left(E_{t}\right)_{\text {sim }}$ values are obtained by multiplying the bin value of $\left(\dot{E}_{t}\right)_{\text {sim }}$ by the corresponding $n_{I_{b}}$ value.

The simplified approach is particularly advantageous, from an application point of view, whenever, for a certain location, an hourly frequency distribution of the DNI is available even when the original hourly-based data series is not. The latter, for example, may be the case when frequency histograms of direct solar radiation are defined synthetically, through either statistical or analytical methods, to represent the average solar radiation conditions of a studied macro-region. In these cases, it is not even strictly necessary to know the exact value of $\bar{T}_{\text {air }}$ corresponding to each bin of $I_{b}$ and it is sufficient to assume a constant value equal to the annual average air temperature of the specific geographical location. The model described by Eqs. 1-4, in fact, shows that the net electricity production of a dish-Stirling system is only slightly sensitive to variations in temperature and mainly depends on the intensity of direct normal irradiance. The simplified method is, also, particularly convenient, in terms of the immediacy the calculations, whenever it is necessary to optimise the design of dish-Stirling collectors as a function of the hourly frequency distribution of direct radiation, especially considering that the linear model used for electricity production simulations (described by Eqs.1-4) can be easily recalibrated to simulate the electrical output of different dish-Stirling systems [35].

When the time period to which the historical climate data series refers is sufficiently long (e.g. 10 years) it is possible to calculate, for each defined bin and for a given location, the annual average values of: the hourly frequency $\bar{n}_{I_{b}}$, the solar direct normal energy $\bar{E}_{s}$ and the net electric output energy calculated both by the hourly-based $\left(\bar{E}_{t}\right)_{h o r}$ and the simplified $\left(\bar{E}_{t}\right)_{\text {sim }}$ approaches (as shown in box (e) in Fig. 1). By comparing the latter two quantities, it was possible to verify the accuracy of the newly proposed simplified method compared to the hourly-based approach.

Preprint version; Please cite this paper as: Buscemi, A., Guarino, S., Ciulla, G., \& Lo Brano, V. (2021). A methodology for optimisation of solar dish-Stirling systems size, based on the local frequency distribution of direct normal irradiance. Applied Energy, 303, 117681. 


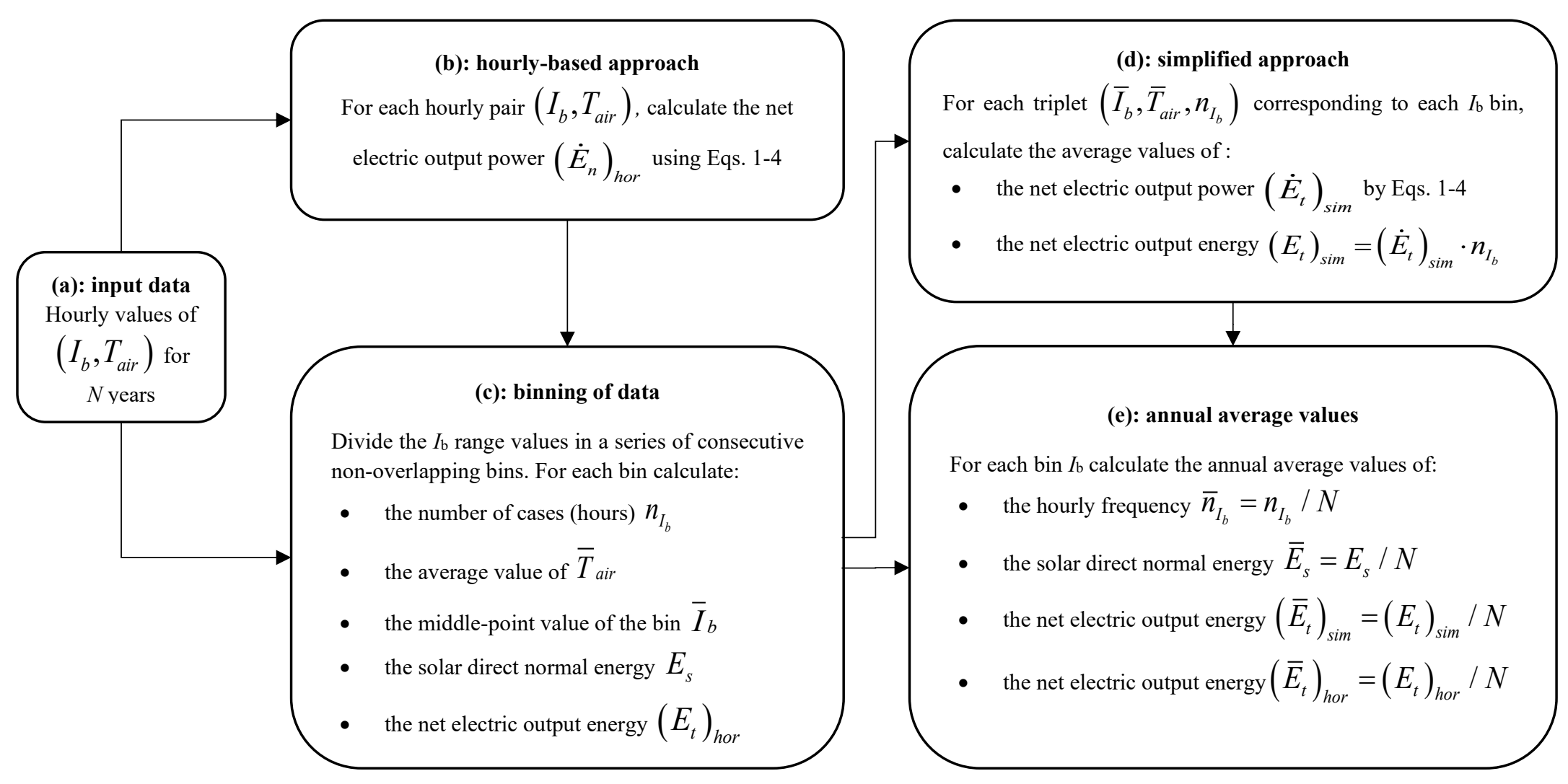

Figure 1: the flowchart of the calculation approaches

Preprint version; Please cite this paper as: Buscemi, A., Guarino, S., Ciulla, G., \& Lo Brano, V. (2021). A methodology for optimisation of solar dish-Stirling systems size, based on the local frequency distribution of direct normal irradiance. Applied Energy, $303,117681$. 


\subsection{LCOE analysis and definition of a new incentive scheme}

In this subsection both the methodology for carrying out the LCOE analyses and the definition of a new incentive scheme for dish-Stirling systems are presented. Based on the results of energy analyses carried out with the numerical approaches described above, the LCOE analyses were developed assuming a trend of reduction over time of the system installed costs. This trend, gauged as a result of the effect of economies of scale, was hypothesised using the installed cost data of the other CSP systems available in the literature for the last decade [11]. Then considering the same cost reduction trend, a new incentive scheme was defined and validated using both the net present value (NPV) and the discounted payback time (DPBT) as economic indicators. The LCOE of an electrical generation system is, in general, defined as the present value of the cost of the produced electricity taking into account the plant lifespan and the costs of construction, of operation and maintenance and of fuel consumption. [51]. In this study, the following LCOE expression was used [11]:

$$
L C O E=\frac{\sum_{t=1}^{n} \frac{I_{t}+M_{t}+F_{t}}{(1+r)^{t}}}{\sum_{t=1}^{n} \frac{E_{t}}{(1+r)^{t}}}\left[\frac{€}{\mathrm{kWh}_{\mathrm{e}}}\right]
$$

where:

- $\quad I_{t}[€]$ is the investment cost occurring in the year $t$

- $\quad M_{t}[€]$ is the Operation and Maintenance (O\&M) costs occurring in the year $t$

- $\quad F_{t}[€]$ is the fossil fuel cost

- $\quad E_{t}[\mathrm{kWh}]$ is the amount of electricity produced in the year $t$

- $\quad r[-]$ is the interest rate used for discounting expenditures and revenues

- $\quad n$ [year] is the lifetime of the power plant under consideration

- $\quad t$ is the $t$-th year of the lifetime of the power plant.

The investment costs $I_{t}$ considered for the LCOE analyses are those occurring at year zero ( $I_{0}$ ). These costs include those of the transport and installation of the system and those of the unit components (the collector mirrors, the PCU, the solar tracking system, the supporting structure, the

Preprint version; Please cite this paper as: Buscemi, A., Guarino, S., Ciulla, G., \& Lo Brano, V. (2021). A methodology for optimisation of solar dish-Stirling systems size, based on the local frequency distribution of direct normal irradiance. Applied Energy, 303, 117681. 
foundation, the weather station, the electric equipment and the cooling system). No economic subsidies or incentives were considered in $I_{t}$.

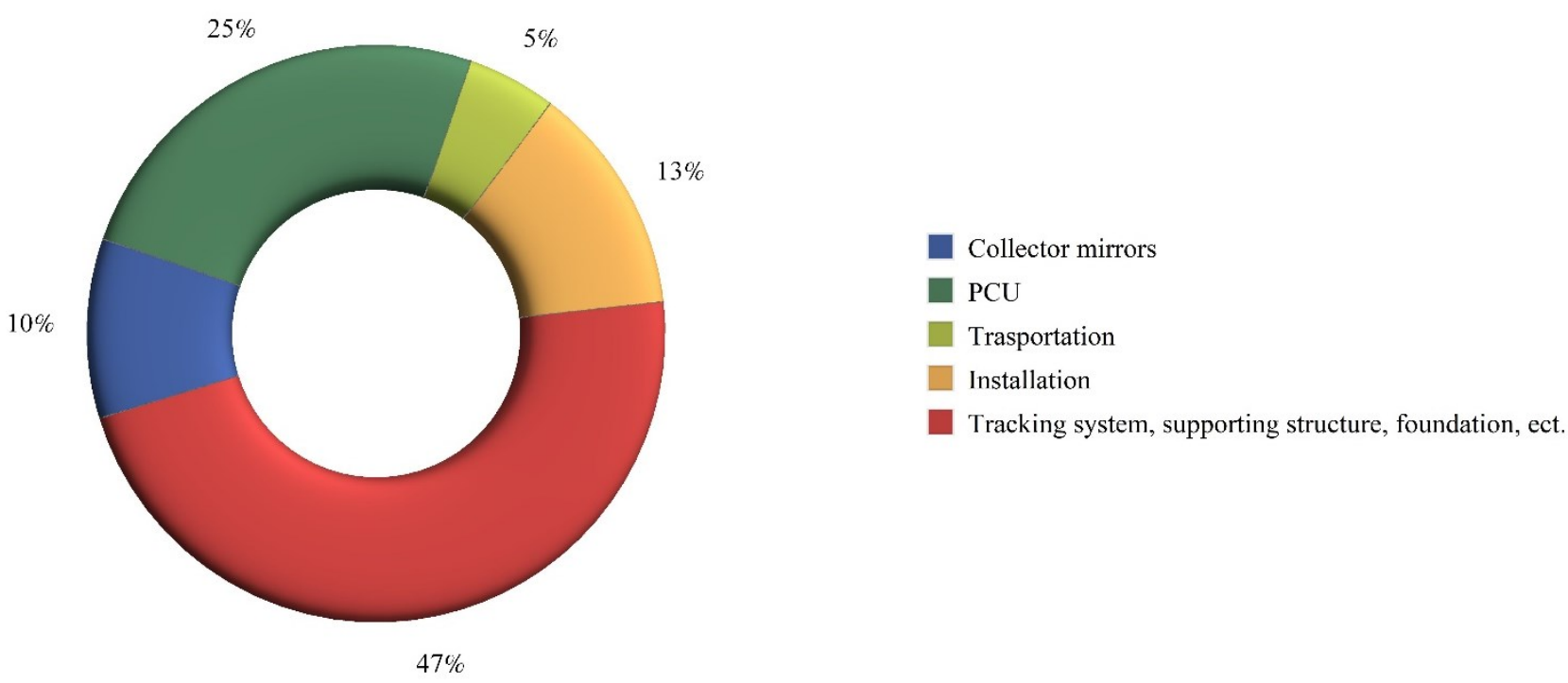

Figure 2: percentage breakdown of total installed costs for the Palermo dish-Stirling unit

The $I_{t}$ of the dish-Stirling unit of Palermo, corresponding to the basic configuration of the 6 units analysed, was assessed considering the real costs afforded for the construction of this plant. The percentage breakdown of the total installed costs of this collector, amounting to $I_{t}=200,525 €$, is depicted in the pie-chart in Fig. 2. From the same figure, it is possible to observe that about $25 \%$ of the total cost is related to the PCU, $10 \%$ to the cost of mirrors and almost $50 \%$ to the cost of solar tracking and support structures. From this data, considering that this plant is characterised by a net peak electrical output power of about $32 \mathrm{~kW}_{\mathrm{e}}$ and a reflector aperture area of $A_{\mathrm{n}, 0}=106 \mathrm{~m}^{2}$, it is possible to deduce the specific costs of both the installed plant and collector mirrors, equal to $6,266.41$ $€ / \mathrm{kW}_{\mathrm{p}}$ and $188.68 € / \mathrm{m}^{2}$ respectively. Compared to the basic module, the other 5 dish-Stirling configurations studied differ only in the extension of the collector aperture areas. Thus, for the latter, the total installed cost was evaluated by only adjusting the amount related to the mirror surface area (evaluated by the unit cost estimated above). Moreover, the annual operation and maintenance costs were fixed to $M_{t}=3,117.68 €$, based on the operation of the dish-Stirling unit of Palermo, and no costs for fuel consumption were considered $\left(F_{t}=0 €\right)$ since dish-Stirling systems do not need fossil fuel for operation [11]. Finally, for the LCOE computations, a discount rate value equal to $r=7.5 \%$

Preprint version; Please cite this paper as: Buscemi, A., Guarino, S., Ciulla, G., \& Lo Brano, V. (2021). A methodology for optimisation of solar dish-Stirling systems size, based on the local frequency distribution of direct normal irradiance. Applied Energy, 303, 117681. 
(as suggested for OECD - Organisation for Economic Co-operation and Development - countries [11]) and a plant lifespan of $n=25$ year were used in Eq. 12.

As anticipated, the effect of the economies of scale, triggered by a greater commercial penetration of this technology, should lead to a progressive reduction in the installed cost over a number of years similar to what happened for the other CSP technologies (parabolic troughs, Fresnel reflectors and solar towers).

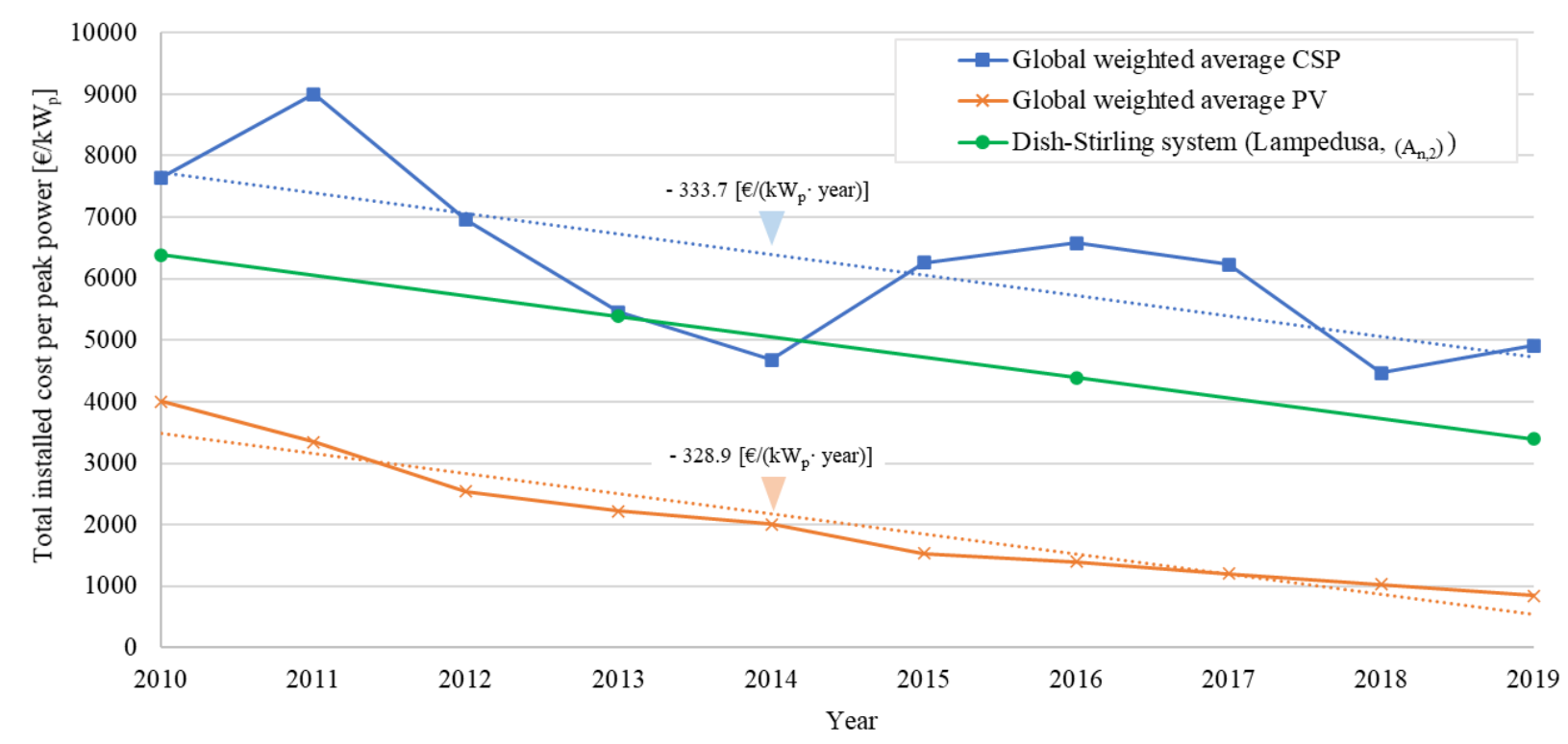

Figure 3: global weighted average total installed costs of CSP and PV systems (2010-2019)

In Fig. 3, the variations of the global average installed costs (per unit of peak electrical power) of both PV systems and CSP systems (excluding dish-Stirling concentrators) are shown for the last decade [11]. In this period, the annual cost reduction trend for CSP systems (indicated with the dotted line in Fig. 3) was about $334 € /\left(\mathrm{kW}_{\mathrm{p}}\right.$-year). A similar trend was observed for PV systems in the same timespan (about $329 € /\left(\mathrm{kW}_{\mathrm{p}}\right.$ ·year)) although their installed costs were lower compared to that of CSP systems (see Fig. 3). Based on these considerations, this work involved simulating the hypothetical time evolution that the LCOE of dish-Stirling systems would have if their installed cost reduction were the same as the other CSP technologies. Under this hypothesis, 6 installed cost time variation functions corresponding to the 6 dish-Stirling configurations studied were defined (in Fig. 3 the cost function of the configuration with $A_{\mathrm{n}, 3}$ is plotted). All these functions have a reduction trend identical to that of the other CSP systems and an initial cost equal to the current cost of each plant configuration. Following this approach, the LCOE variations in 10 years were simulated for the 6 collector configurations and for all the analysed geographical locations.

Preprint version; Please cite this paper as: Buscemi, A., Guarino, S., Ciulla, G., \& Lo Brano, V. (2021). A methodology for optimisation of solar dish-Stirling systems size, based on the local frequency distribution of direct normal irradiance. Applied Energy, 303, 117681. 
As mentioned above, a new incentive scheme, finalised to encourage the diffusion of dish-Stirling systems is introduced with this work. To test this incentive scheme, the NPV and the DPBT were assessed for all the 42 studied cases. The $N P V$ was calculated according to the following definition:

$$
N P V=\sum_{t=1}^{n} \frac{C F_{t}}{(1+r)^{t}} \quad[€]
$$

where: $n$ is the lifespan of the plant (equal to 25 years), $t$ is the $t$-th year of the lifetime of the project, $C F_{\mathrm{t}}[€]$ is the corresponding cash flow and $r[-]$ is the interest rate (assumed equal to $7.5 \%$ ). On the other hand, the DPBT [year], defined as the number of years $t$ needed for the equivalent of the investment income to exceed the equivalent of the capital expenditure, was determined according to the following relation:

$$
D P B T=t \quad \mid \sum_{t=0}^{n} \frac{C F_{t}}{(1+r)^{t}} \geq 0 \quad[\text { year }]
$$

In the above relationships, the cash flow, for year zero $(t=0)$ was fixed to the investment plant cost, while for the years that followed $(t>0)$, it was calculated considering the annual operation and maintenance costs of the plant and the revenue from the sale of the annual electric energy delivered to the national grid:

$$
C F_{t}:=\left\{\begin{array}{ll}
I_{0} & \text { for } t=0 \\
E_{t} \cdot T_{\text {feed-in }}^{(i)}-M_{t} & \text { for } t>0
\end{array} \quad[€]\right.
$$

where $T_{\text {feed-in }}^{(i)}[€]$ is the feed-in tariffs for a plant installed in the same calendar year $i$ since the beginning of the incentive plan, and $t$ is the number of plant operation years since the $i$-th year. The feed-in tariffs introduced in Eq. 16 for the calculation of both NPV and DPBT were defined according to the new incentive scheme for which the rationale is described below.

In order to take into account that the installation costs of the plants will reduce during the incentivization period, a feed-in tariff decreasing over time was defined. Thus, plants that will be built in a certain year $i$ of the incentive period will benefit from a slightly lower feed-in tariff $T_{\text {feed-in }}^{(i)}$ than plants that were built the previous year $T_{\text {feed-in }}^{(i-1)}$, and so on. However, the designated feed-in tariff for plants that will be built in the same year will remain constant throughout the incentive period.

Preprint version; Please cite this paper as: Buscemi, A., Guarino, S., Ciulla, G., \& Lo Brano, V. (2021). A methodology for optimisation of solar dish-Stirling systems size, based on the local frequency distribution of direct normal irradiance. Applied Energy, 303, 117681. 
The following assumptions were made in order to construct the reduction function of the feedin tariff over time: (1) the reduction trend of the installation cost over time is equal to that of the global weighted installed cost of CSP systems; (2) the DPBT is equal for all plants having the same collector opening area, regardless of the year of their construction. In other words, this proposed incentive mechanism aims to find a trade-off between the interests of CSP investors and those of the local governments providing the incentive: on the one hand, investors will be able to achieve a nearconstant DPBT of their investments regardless of the year of plant construction; on the other hand, governments will be able to rationally reduce the economical charge of the incentive system over time, taking into account the reduction in the installed cost of the technology thanks to economies of scale.

Thus, by manipulating Eqs. 13-14, according to these assumptions, the feed-in tariff variations of plants falling under the incentive plan at the $i$-th year can be expressed as follows:

$$
T_{\text {feed-in }}^{(\mathrm{i})}=\frac{I_{0}^{(\mathrm{i})}}{I_{0}^{(0)}} \cdot\left(T_{\text {feed-in }}^{(0)}-\frac{M_{t}}{E_{t}}\right)+\frac{M_{t}}{E_{t}} \quad[€ / \mathrm{kWh}]
$$

Where, $I_{0}^{(\mathrm{i})}$ is the plant installed cost at the $i$-th year from the entry into force of the incentive plan (e.g. the linear function already depicted in Fig. 3 for dish-Stirling concentrators).

It is worth noting from Eq. 16 how general this incentive scheme is and how easily it can be specialised for different geographic macro-areas and for different dish-Stirling systems. In fact, while the variation of the $\frac{I_{0}^{(\mathrm{i})}}{I_{0}^{(0)}}$ ratio over time is essentially a global decreasing trend (see Fig. 3), the values of $I_{0}, M_{t}$ and $E_{t}$ depend both on the particular dish-Stirling system and on the local availability of direct solar irradiation. Finally, the initial feed-in tariff $T_{\text {feed-in }}^{(0)}$ can be tuned to ensure an attractive DPBT for investors. This initial tariff can be also compared with that dedicated to other solar power systems.

In order to test the validity of this approach, the incentive scheme proposed above was calibrated for the Italian territory considering both the calculated energy productions for dish-Stirling plants installed in this geographical area and the structure of the old Italian incentive scheme dedicated to renewable energy sources [52]. According to this plan, which is no longer in force in Italy, the feed-in tariff for CSP systems was obtained as the sum of two components: a base incentive tariff $T_{\mathrm{b}}[€ / \mathrm{kWh}]$ (depending on the plant size) and a bonus $P_{\mathrm{r}, \text { solar }}[€ / \mathrm{kWh}$ ] (proportional to the solar integration fraction of the plant). In the new incentive scheme proposed in this study, the bonus Preprint version; Please cite this paper as: Buscemi, A., Guarino, S., Ciulla, G., \& Lo Brano, V. (2021). A methodology for optimisation of solar dish-Stirling systems size, based on the local frequency distribution of direct normal irradiance. Applied Energy, 303, 117681. 
component was maintained identical to that of the old decree for CSP systems $\left(P_{\mathrm{r} \text {,solar }}=0.045 € / \mathrm{kWh}_{\mathrm{e}}\right)$, while the basic incentive tariff was increased and set to $T_{\mathrm{b}}=0.415 € / \mathrm{kWh}$. In this way, the feed-in tariff for the first calendar year of the incentive plan was set to $T_{\text {feed-in }}^{(0)}=0.46 € / \mathrm{kWh}$ which is equal to the feed-in tariff of the first Italian incentive plan dedicated to PV plants (decree of 28 July 2005 [53]). Thus, introducing both $T_{\text {feed-in }}^{(0)}$ and $E_{\mathrm{t}}$ as parameters in Eq. 16 and assuming the installed cost functions $I_{0}^{(\mathrm{i})}$, already employed for LCOE analyses, it was possible to determine a $T_{\text {feed-in }}^{(\mathrm{i})}$ function for each of the 42 studied cases hereinafter defined. Then these functions were averaged in order to define a single regional feed-in tariff function. Finally, this function was introduced in Eqs. 12-13 to assess the NPV and DPBT of all the studied cases with the aim of testing the validity of the proposed incentive scheme.

\section{CASE STUDIES}

In this work, the procedure proposed above was used to assess the energy performance of dish-Stirling concentrators installed in different locations in the central Mediterranean. The dishStirling system that was chosen as a reference for the energy evaluations is a real commercial collector currently operating at the facility test site at Palermo University (see Fig. 4). This plant is characterised by a reflector aperture area of $A_{\mathrm{n}, 0}=106 \mathrm{~m}^{2}$ and a net peak electrical output power of about $32 \mathrm{~kW}_{\mathrm{e}}$ [35]. In November 2012, a plant similar to this one, but located in South Africa, set the current world record for solar-to-electricity conversion efficiency, making this particular dish-Stirling a state-of-the-art system in the CSP sector.

Preprint version; Please cite this paper as: Buscemi, A., Guarino, S., Ciulla, G., \& Lo Brano, V. (2021). A methodology for optimisation of solar dish-Stirling systems size, based on the local frequency distribution of direct normal irradiance. Applied Energy, 303, 117681. 


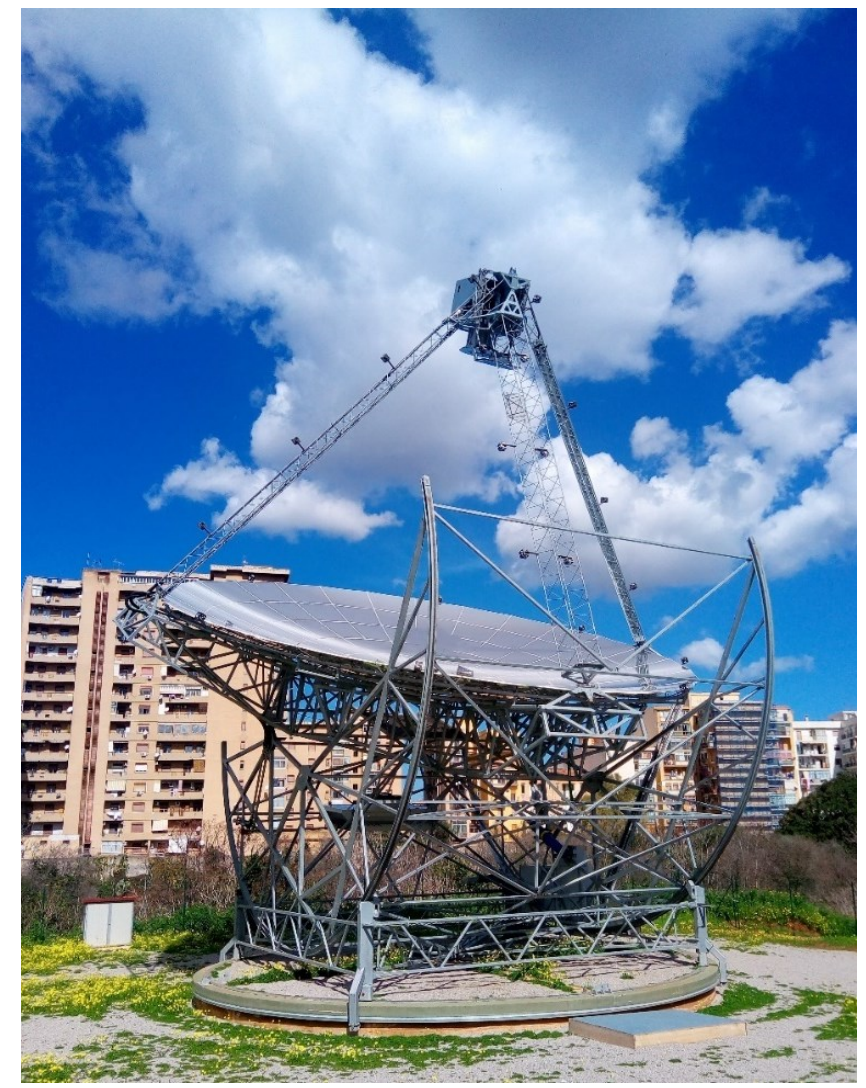

Figure 4: the dish-Stirling plant of Palermo

Five additional dish-Stirling configurations were also considered for the study. These latter systems were hypothesised to have the same PCU (i.e. the same Stirling engine) as the real collector model from which they differ in both the reflector size (see Fig. 5) and in the implementation of a receiver cooling system. This cooling device, assumed to be similar to that developed for the SBP EuroDish units [29], allows the dissipation of the solar energy surplus that is concentrated in the PCU receiver during the peaks of solar irradiance. This energy surplus, in turn, is related to the fact that the reflector aperture areas of the modified configurations were assumed to be larger than the basic one. The aperture areas of these five CSP systems are equal to $A_{\mathrm{n}, 1}=116.6 \mathrm{~m}^{2}, A_{\mathrm{n}, 2}=127.2 \mathrm{~m}^{2}, A_{\mathrm{n}, 3}=$ $137.8 \mathrm{~m}^{2}, A_{\mathrm{n}, 4}=148.4 \mathrm{~m}^{2}, A_{\mathrm{n}, 5}=159 \mathrm{~m}^{2}$, respectively.

Preprint version; Please cite this paper as: Buscemi, A., Guarino, S., Ciulla, G., \& Lo Brano, V. (2021). A methodology for optimisation of solar dish-Stirling systems size, based on the local frequency distribution of direct normal irradiance. Applied Energy, 303, 117681. 


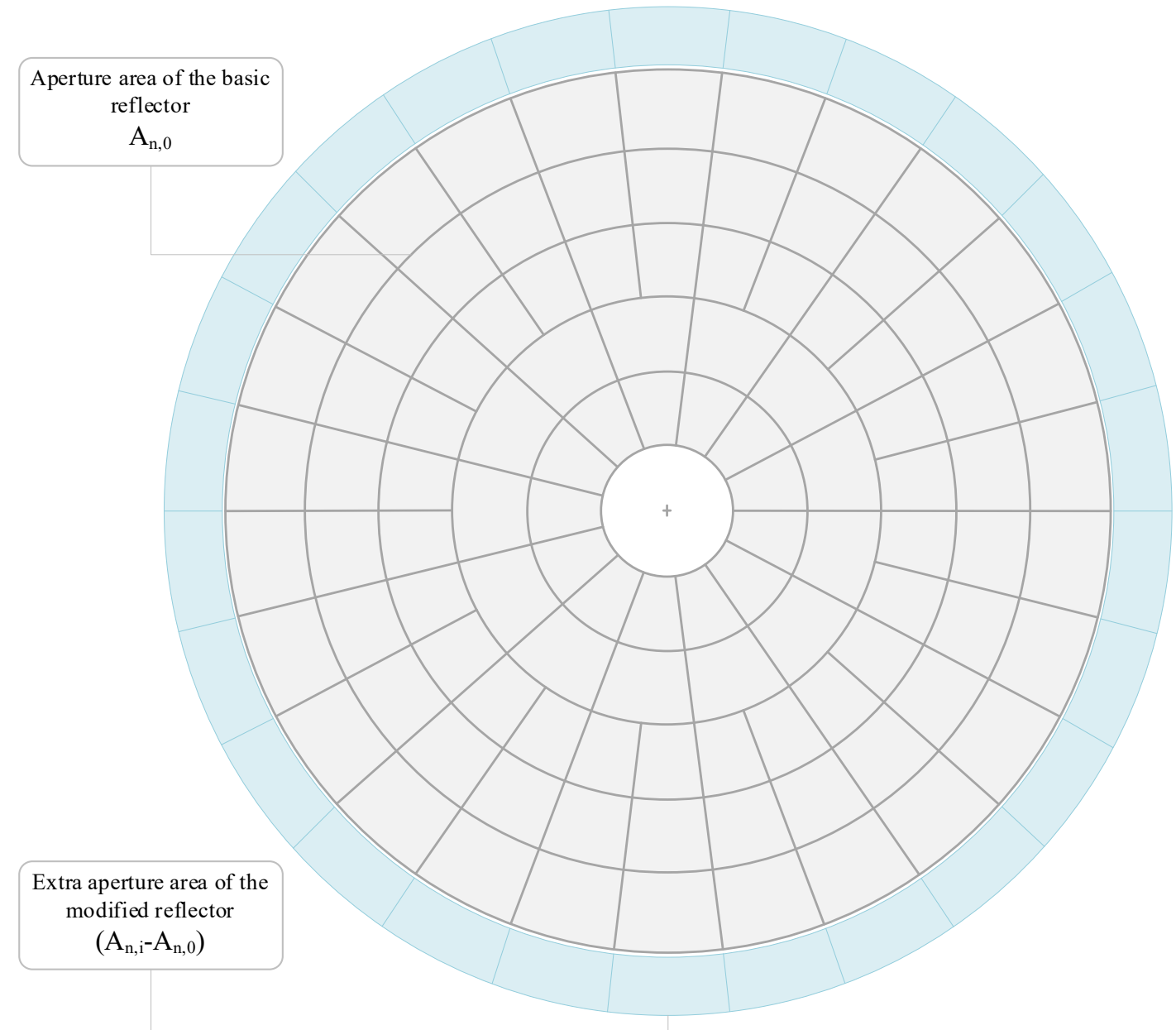

Figure 5: representation of reflector aperture area for modified dish-Stirling system configurations

In order to evaluate the dish-Stirling energy production as a function of various solar irradiation levels, seven locations, each characterised by different hourly frequency distributions of DNI, were considered for the analyses. These plant locations, which are all on the southern side of the Italian territory (see Fig. 6), are the following: Lampedusa, Cagliari, Ragusa, Palermo, Brindisi, Rome, and Naples. Considering the 6 collector configurations and the 7 plant locations, the total number of case studies that are examined in this study amounts to 42. As described in more detail further on in this article, hourly-based numerical simulations were carried out in order to define the electric energy production of all these 42 studied cases. These simulations were performed assuming two different DNI time-series for each location as input.

Preprint version; Please cite this paper as: Buscemi, A., Guarino, S., Ciulla, G., \& Lo Brano, V. (2021). A methodology for optimisation of solar dish-Stirling systems size, based on the local frequency distribution of direct normal irradiance. Applied Energy, 303, 117681. 


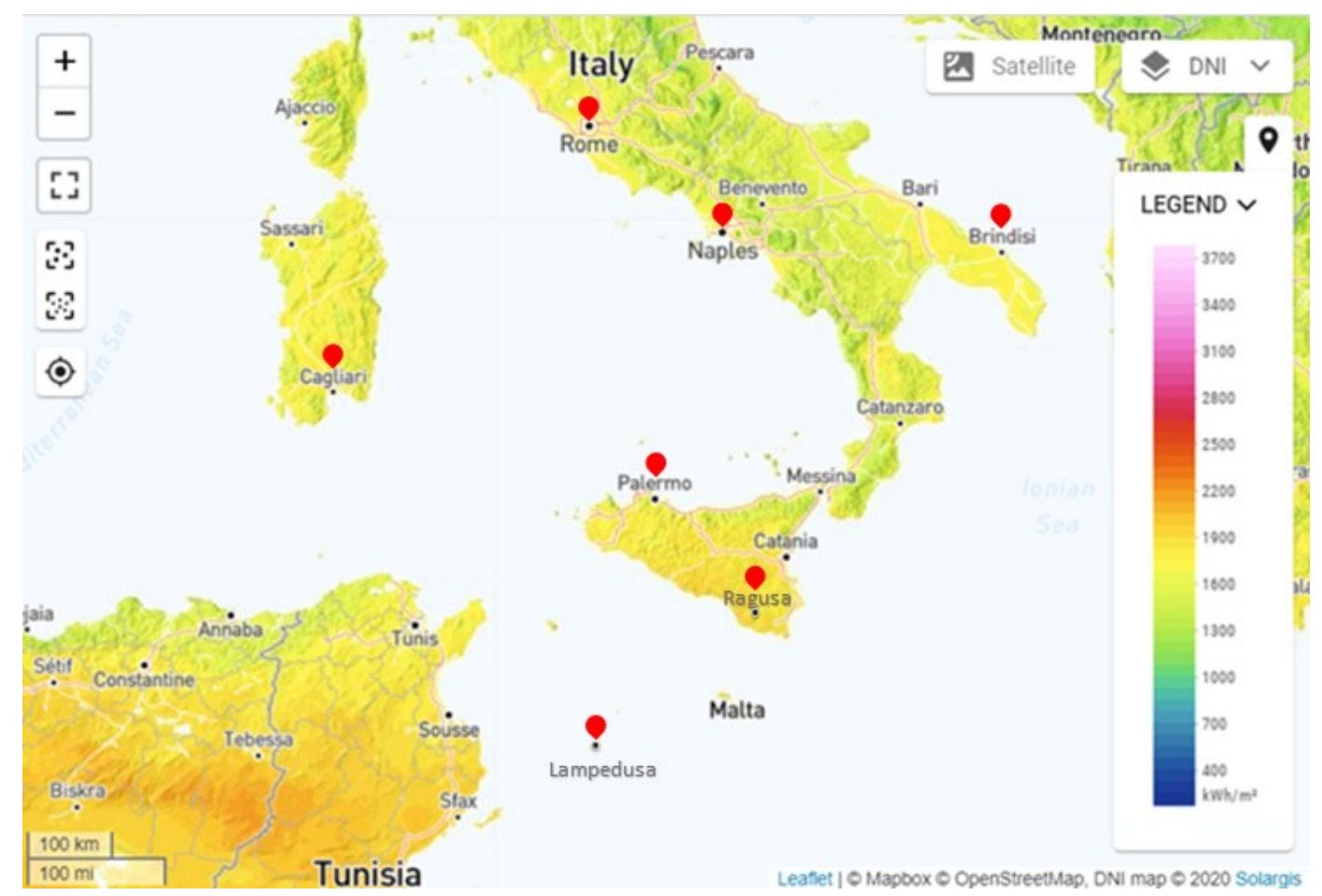

Figure 6: iso-map of DNI and locations of the studied CSP plants (after SOLARGIS)

Thus, using the methods described in the flowchart of Fig. 1, it was possible to produce the following histograms:

- 14 frequency histograms of 1-hour DNI series generated using the two solar datasets for each of the 7 locations. The average values of the air temperature of each bin were represented on the same graphs (following the calculation flow described by boxes (a), (c) and (e) in Fig. 1).

- 84 histograms representing the net electric output energy of the 42 studied cases generated by the hourly-based calculation approach using the two solar datasets (following the calculation flow described by boxes (a), (b), (c) and (e) in Fig. 1).

- 42 histograms representing the net electric output energy for all the 42 studied cases, using the simplified approach with the PVGIS dataset as input (following the calculation flow described by boxes (a), (c), (d) and (e) in Fig. 1).

\section{RESULTS AND DISCUSSION}

Using the hourly series of DNI values provided by both the TMY of Meteonorm and satellite solar data of PVGIS (recorded between 2007 and 2016), the annual average direct solar irradiance values were obtained for all the studied locations and these are summarised in Tab. 2. From the analysis of

Preprint version; Please cite this paper as: Buscemi, A., Guarino, S., Ciulla, G., \& Lo Brano, V. (2021). A methodology for optimisation of solar dish-Stirling systems size, based on the local frequency distribution of direct normal irradiance. Applied Energy, 303, 117681. 
this data, it is possible to observe that the cumulative values of direct solar energy extrapolated from the two datasets deviate from each other by a relative mean percentage difference of about $12 \%$, with a maximum value of about $30 \%$ (in the case of Rome). These differences are not only in the total values of energy but also in how these cumulated quantities are distributed over the different classes of DNI levels, as the data depicted in Figs. 7-8 show.

Table 2: annual direct solar irradiation for the studied locations (PVGIS and Meteonorm)

\begin{tabular}{lcccc}
\hline Location & Longitude & Latitude & \multicolumn{2}{c}{$\begin{array}{c}\text { Direct annual solar irradiation } \\
\left(\mathrm{kWh} / \mathrm{m}^{2} / \text { year }\right)\end{array}$} \\
& (Decimal degrees) & PVGIS & Meteonorm \\
\hline Brindisi & 17.943 & 40.673 & 1840 & 1791 \\
\hline Cagliari & 9.117 & 39.267 & 2009 & 1704 \\
\hline Lampedusa & 12.617 & 35.503 & 2058 & 1948 \\
\hline Naples & 14.330 & 40.844 & 1825 & 1615 \\
\hline Palermo & 13.345 & 38.104 & 1819 & 2138 \\
\hline Ragusa & 14.657 & 37.091 & 1975 & 1311 \\
\hline Rome & 12.566 & 41.783 & 1810 & \\
\hline
\end{tabular}

These figures, in fact, represent the frequency histograms of one-hour $I_{b}$ series for the 7 considered locations. This data was elaborated by using the calculation method described in the flowchart of Fig. 1 fixing a bin width of $\Delta I_{b}=50 \mathrm{~W} / \mathrm{m}^{2}$. The histograms produced with PVGIS data (continuous lines in Figs. 7-8) show, for all the locations, an annual peak hourly frequency (ranging between $\bar{n}_{I_{b}}=700$ 800 hours per year) at DNI levels between 700 and $800 \mathrm{~W} / \mathrm{m}^{2}$. On the other hand, those deduced from Meteonorm data (dashed lines in Figs. 7-8) show either flat distributions (e.g. for Brindisi, Cagliari, Rome and Naples) or distributions having peaks for DNI classes either below $700 \mathrm{~W} / \mathrm{m}^{2}$ (e.g. for Lampedusa and Palermo) or above $800 \mathrm{~W} / \mathrm{m}^{2}$ (e.g. for Ragusa).

Preprint version; Please cite this paper as: Buscemi, A., Guarino, S., Ciulla, G., \& Lo Brano, V. (2021). A methodology for optimisation of solar dish-Stirling systems size, based on the local frequency distribution of direct normal irradiance. Applied Energy, 303, 117681. 


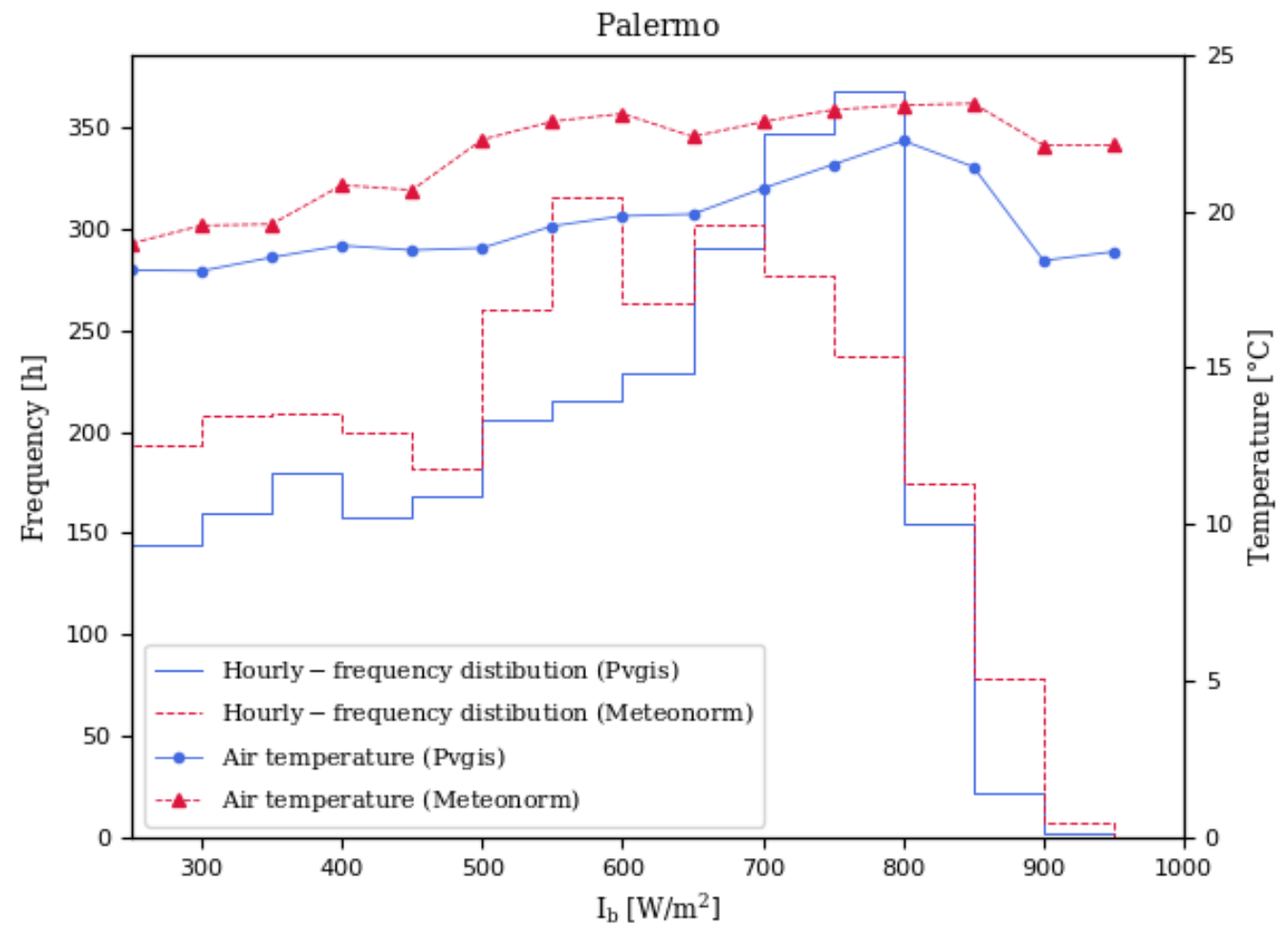

Figure 7: frequency histograms of 1-hour $I_{b}$ series and $\bar{T}_{\text {air }}$ bin values for the site of Palermo (elaborated using both Meteonorm and PVGIS datasets)

Preprint version; Please cite this paper as: Buscemi, A., Guarino, S., Ciulla, G., \& Lo Brano, V. (2021). A methodology for optimisation of solar dish-Stirling systems size, based on the local frequency distribution of direct normal irradiance. Applied Energy, 303, 117681. 

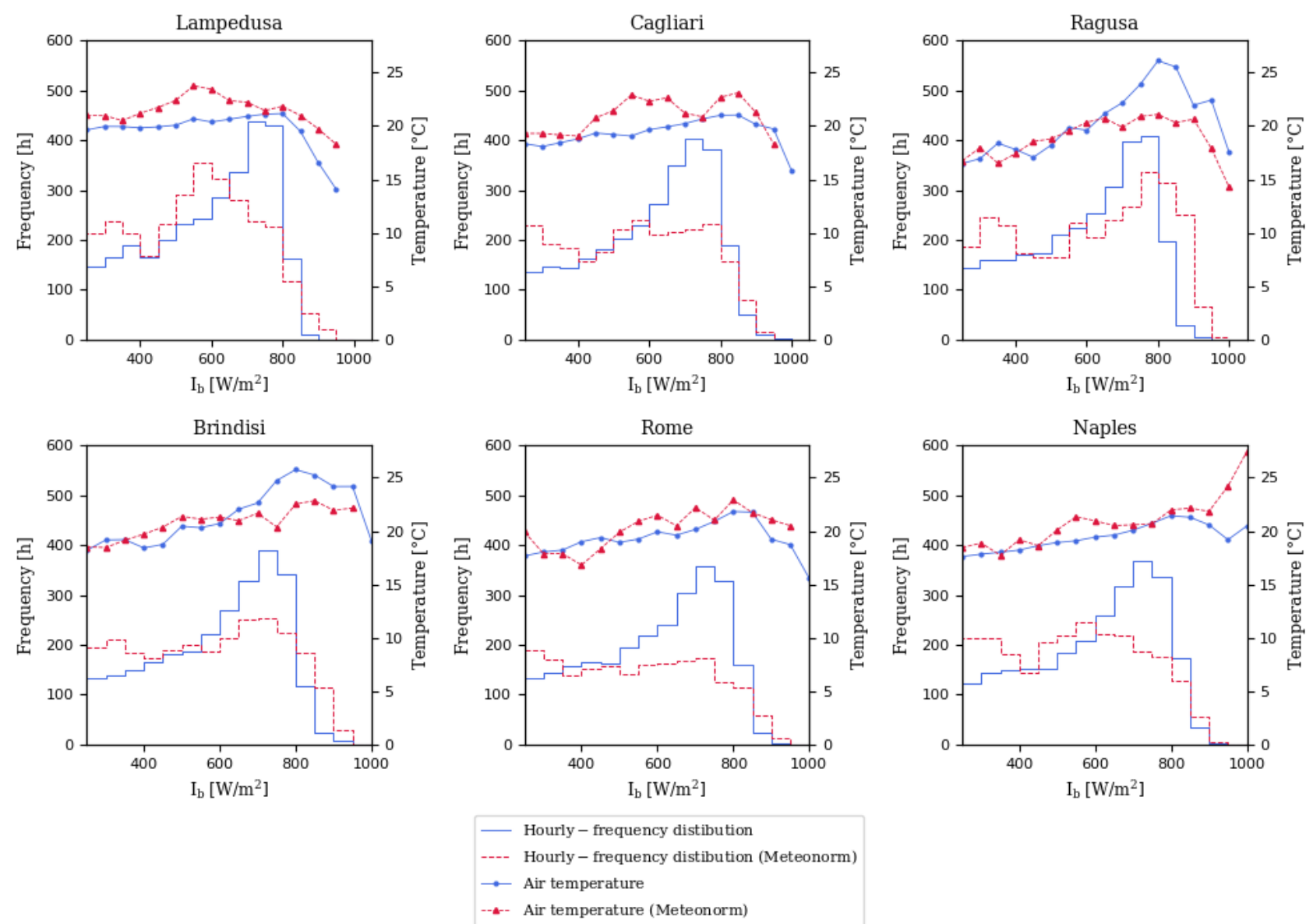

Figure 8: frequency histograms of 1-hour $I_{b}$ series and $\bar{T}_{\text {air }}$ bin values for 6 locations (elaborated using both Meteonorm and PVGIS datasets)

For example, in the case of Palermo (see Fig. 7), even though the cumulative average annual energy deduced from the two solar databases differs only by $6 \%$ (see Tab. 2), the corresponding histograms show peaks at different $I_{b}$ class intervals (about $700-800 \mathrm{~W} / \mathrm{m}^{2}$ for PVGIS and $550-700 \mathrm{~W} / \mathrm{m}^{2}$ for Meteonorm). In the same Figs. 7-8, in each $I_{b}$ bin, the annual average value of the air temperature $\bar{T}_{\text {air }}$ (calculated according to the approaches described by the flowchart in Fig. 1) was also represented using both Meteonorm and PVGIS datasets. For all the locations analysed, these results generally show that $\bar{T}_{\text {air }}$ is an increasing function of $I_{b}$ up to about $I_{b}=900 \mathrm{~W} / \mathrm{m}^{2}$, while for higher values of $I_{b}, \bar{T}_{\text {air }}$ decreases slightly. This behaviour can be justified by analyzing the climate data that characterizes the central area of the Mediterranean basin, since:

Preprint version; Please cite this paper as: Buscemi, A., Guarino, S., Ciulla, G., \& Lo Brano, V. (2021). A methodology for optimisation of solar dish-Stirling systems size, based on the local frequency distribution of direct normal irradiance. Applied Energy, 303, 117681. 
- the hours in which $I_{b}$ is between $250-400 \mathrm{~W} / \mathrm{m}^{2}$ are equally distributed across all seasons. During these periods the average air temperatures are between $T_{\text {air }}=12{ }^{\circ} \mathrm{C}$ (winter) and $T_{\text {air }}$ $=24{ }^{\circ} \mathrm{C}$ (summer)

- the hours in which $I_{b}$ is between $400-900 \mathrm{~W} / \mathrm{m}^{2}$ are mainly concentrated in the warmer seasons (spring and summer). During these periods, the average air temperature is about $T_{\text {air }}$ $=20^{\circ} \mathrm{C}$

- finally, the hours during which $I_{b}$ is between $900-950 \mathrm{~W} / \mathrm{m}^{2}$ (according to days characterised by clear skies and low air turbidity) are mainly concentrated in spring and winter. During these periods, the average air temperature is about $T_{\text {air }}=18^{\circ} \mathrm{C}$

For the basic collector configuration $A_{\mathrm{n}, 0}$ (corresponding to the existing dish-Stirling plant of Palermo), the annual net electric energy distributions, as a function of the different $I_{b}$ classes, were calculated using the methods described in the flowchart in Fig. 1 and are represented by the histograms in Figs. 9-10 for each of the 7 plant locations. From the results represented in Fig. 9, it is possible to observe that the productions calculated with the PVGIS solar dataset for the location of Palermo through both the simplified method and the hourly method are practically identical (with an overall relative percentage error of around $0.03 \%$ ). This result is particularly interesting because it demonstrates that it is possible to accurately simulate the annual electricity production of a dishStirling system from the frequency histograms of 1-hour $I_{b}$ series only. This is possible also because the energy model described by Eqs. 1-4 is not particularly sensitive to the variations of $T_{\text {air }}$.

Preprint version; Please cite this paper as: Buscemi, A., Guarino, S., Ciulla, G., \& Lo Brano, V. (2021). A methodology for optimisation of solar dish-Stirling systems size, based on the local frequency distribution of direct normal irradiance. Applied Energy, 303, 117681. 


\section{Palermo}

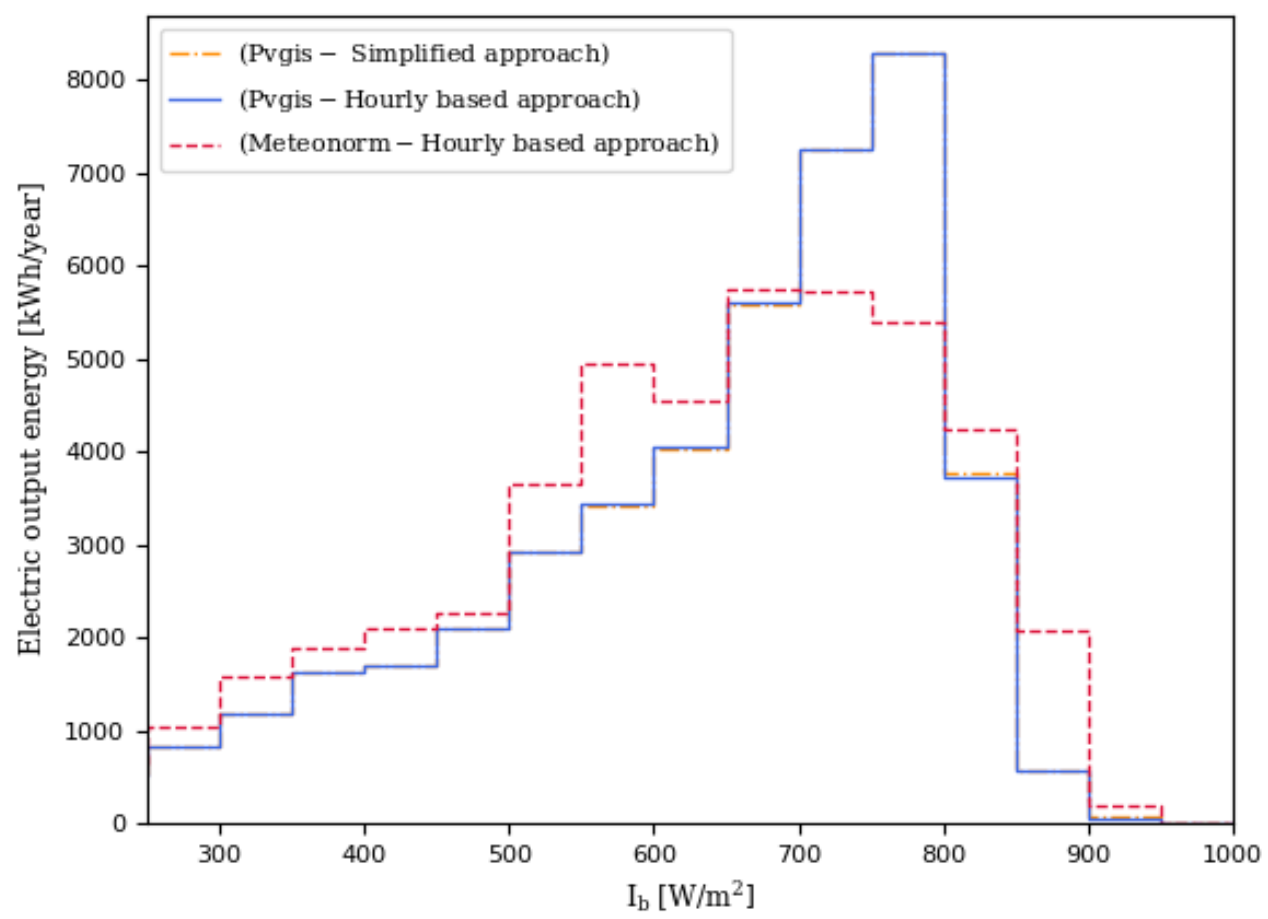

Figure 9: annual electric output energy as a function of $I_{b}$ classes for the dish-Stirling plant of Palermo ( $A_{\mathrm{n}, 0}$ configuration)

Preprint version; Please cite this paper as: Buscemi, A., Guarino, S., Ciulla, G., \& Lo Brano, V. (2021). A methodology for optimisation of solar dish-Stirling systems size, based on the local frequency distribution of direct normal irradiance. Applied Energy, 303, 117681. 

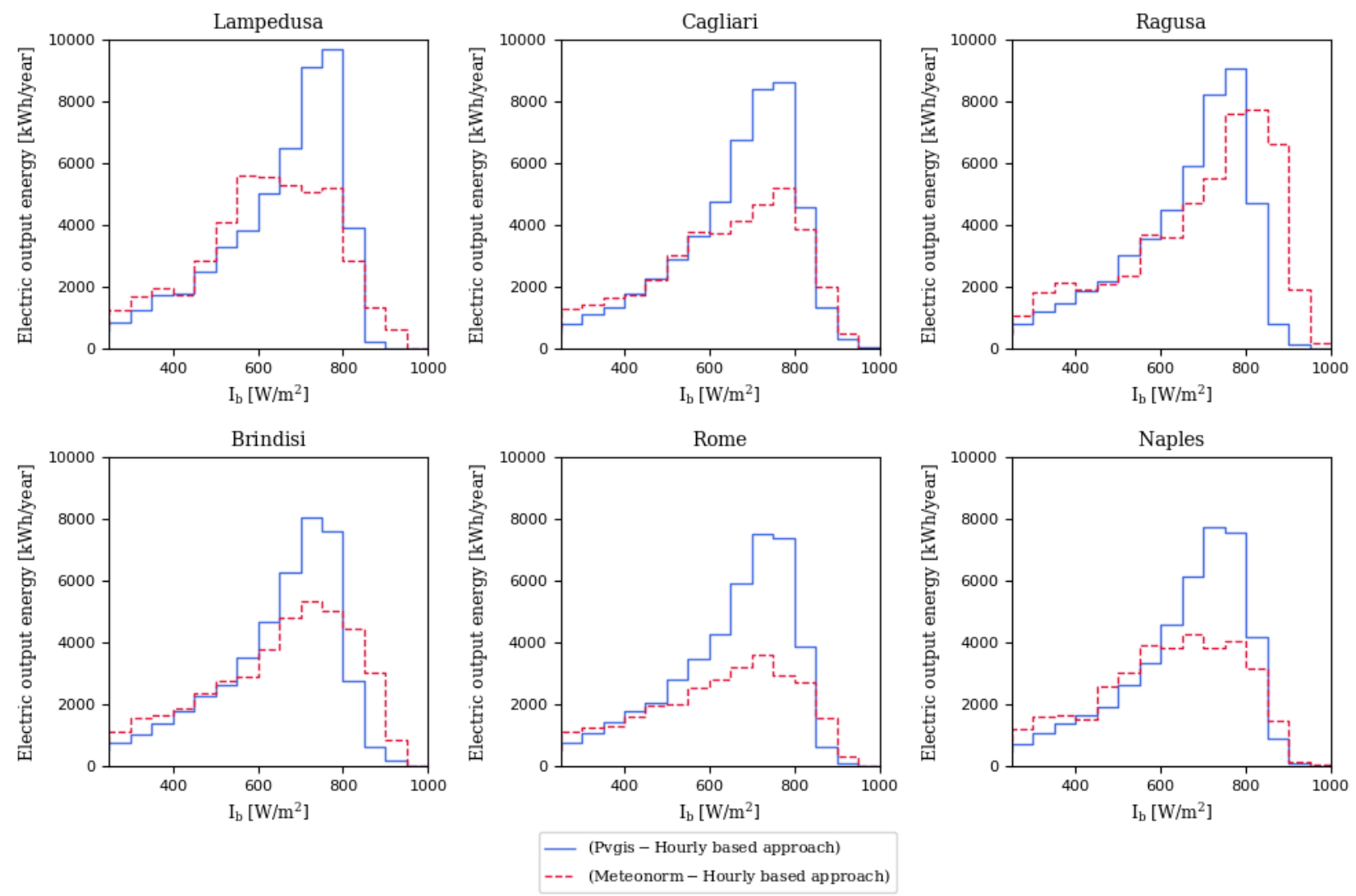

Figure 10: annual electric output energy as a function of $I_{b}$ classes for the $A_{\mathrm{n}, 0}$ dish-Stirling configuration at 6 different locations (elaborated using both Meteonorm and PVGIS datasets)

This new approach may be used, for example, to allow the collector optimization in a macro-climatic area using the typical frequency histograms of 1-hour $I_{b}$ series that can be generated through suitable statistical methods. For what concerns, instead, the comparison between the results obtained with the hourly approach using the two solar datasets, it is possible to notice from Figs. 9-10, that the differences between these results is essentially a consequence of the differences between the hourly frequency histograms of DNI (see Figs. 7-8). Another interesting observation is that the differences between the annual electrical energies calculated using Meteonorm and PVGIS do not coincide with those between the direct annual solar irradiation values defined by the same datasets (see Tab. 2). For example, in the case of Palermo (see Fig. 9), the annual net electrical energy output calculated by Meteonorm amounts to $E_{t}=46 \mathrm{MWh}_{\mathrm{e}}$, while the corresponding energy value calculated by PVGIS amounts to $E_{t}=43.84 \mathrm{MWh}_{\mathrm{e}}$. The percentage deviation between these values is $4.8 \%$, while that between the annual solar direct irradiation values for the same location calculated from Tab. 2 is about

Preprint version; Please cite this paper as: Buscemi, A., Guarino, S., Ciulla, G., \& Lo Brano, V. (2021). A methodology for optimisation of solar dish-Stirling systems size, based on the local frequency distribution of direct normal irradiance. Applied Energy, 303, 117681. 
$6 \%$. The same comparative analysis was extended to the other 6 locations yielding similar qualitative results, as summarised in Fig. 11.

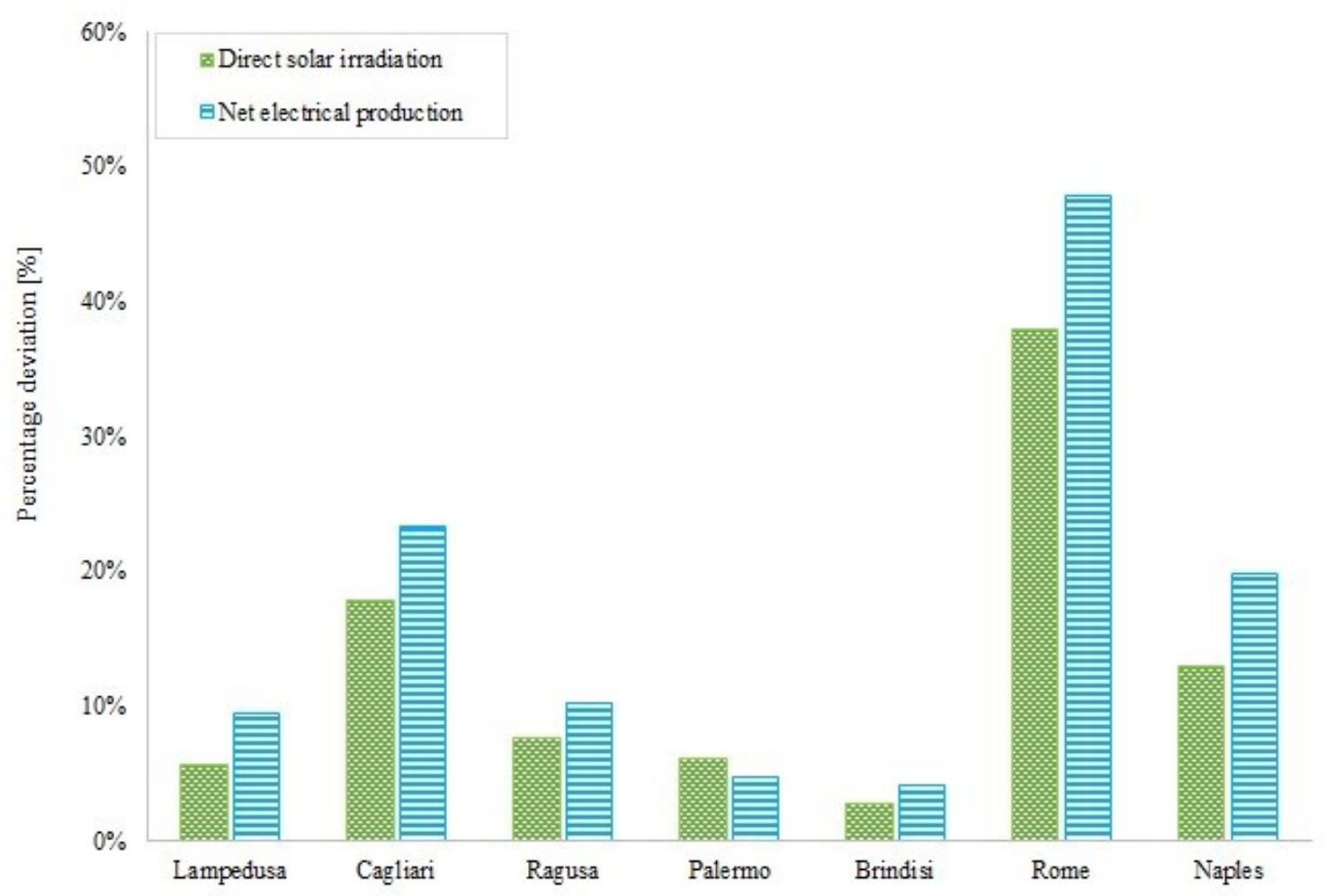

Figure 11: percentage deviations between the values of the annual DNI and $E_{t}$ calculated using PVGIS and Meteonorm, respectively

From the data represented in this figure what stands out, for example in the case of Rome, is that where the percentage difference between the input solar irradiation values is about $38 \%$, that between the production values is $47.8 \%$. This non-proportionality between input and output energy differences is essentially related to the fact that the solar-to-electric conversion efficiency of a dish-Stirling system (calculated according to Eq. 10) weighs the various levels of input solar irradiance differently (see Fig. 12). In summary, these first results underline what the impact could be of an incorrect definition of the DNI hourly frequency histograms on the energy prediction accuracy of a dishStirling system at a given location.

Preprint version; Please cite this paper as: Buscemi, A., Guarino, S., Ciulla, G., \& Lo Brano, V. (2021). A methodology for optimisation of solar dish-Stirling systems size, based on the local frequency distribution of direct normal irradiance. Applied Energy, 303, 117681. 


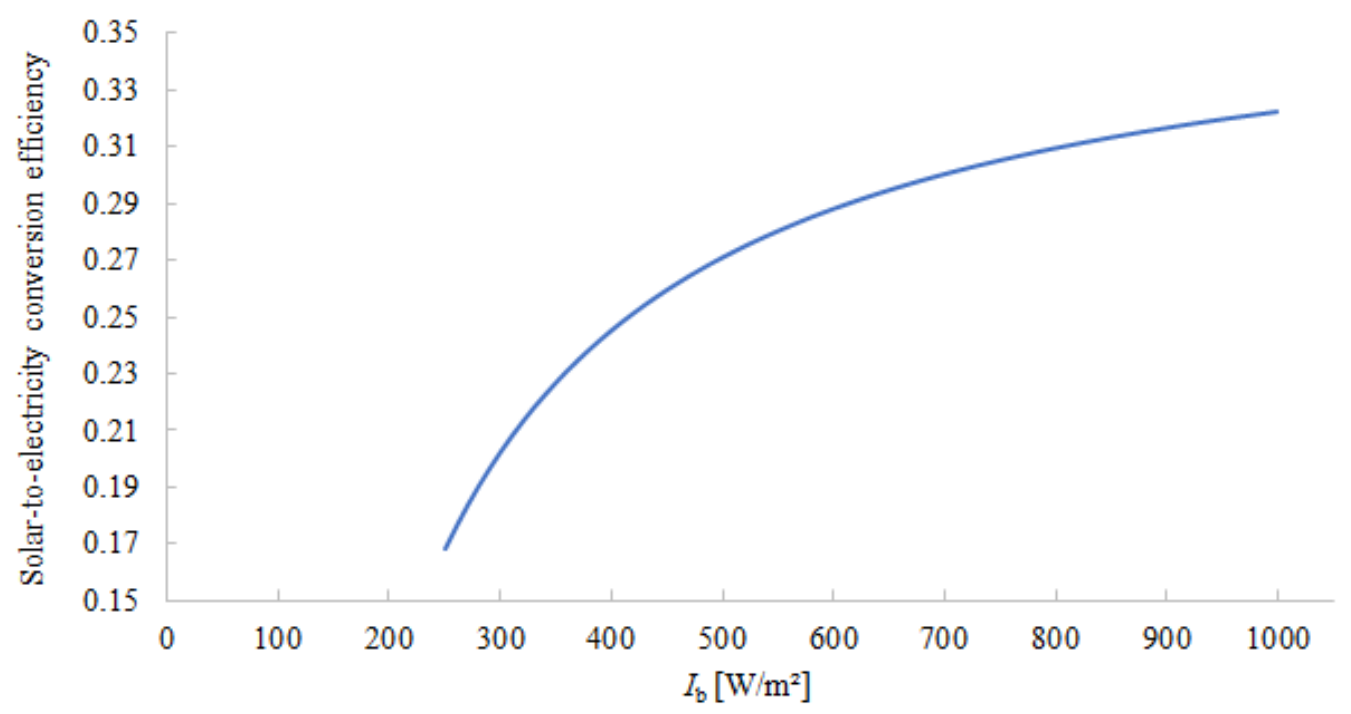

Figure 12: instantaneous solar-to-electric conversion efficiency curve as a function of direct normal solar irradiance with $T_{\text {air }}=25^{\circ} \mathrm{C}$ and clean mirrors (see Eq. 10)

Based on these considerations, for the purpose of the analysis presented below, the DNI data deduced by PVGIS was considered more useful than that of Meteonorm, since:

- the solar data from PVGIS is based on real satellite measurements carried out over several years at the studied locations

- the major uncertainties in this data mainly correspond to the lower levels of DNI (mostly on cloudy days). These solar irradiance levels have a negligible impact on the accuracy of the annual energy production determinations as it possible to deduce from the efficiency curve in Fig. 12.

Moreover, PVGIS data shows that the annual hourly frequency peaks of DNI, for all the considered locations, correspond to DNI values ranging between 700 and $800 \mathrm{~W} / \mathrm{m}^{2}$. However, the dish-Stirling configuration of Palermo was optimised for a peak power of $I_{b}=900 \mathrm{~W} / \mathrm{m}^{2}$, which is an irradiance level occurring only for a small number of hours per year in the Mediterranean area. Therefore, in this study, following a strategy similar to that reported in the literature for the EuroDish systems [29], The possibility of reducing the $I_{b}$ value corresponding to the peak output power of the Stirling engine by both increasing the collector aperture area $A_{\mathrm{n}}$ and using a thermal dissipater in the receiver to manage $\dot{Q}_{S, \text { in }}$ greater than $\dot{Q}_{S, \text { in }}^{\max }$ was investigated. The net electrical output powers as a function of $I_{b}$ variations for the 6 collectors were calculated using Eqs. 1-10 and these are depicted in Fig. 13.

Preprint version; Please cite this paper as: Buscemi, A., Guarino, S., Ciulla, G., \& Lo Brano, V. (2021). A methodology for optimisation of solar dish-Stirling systems size, based on the local frequency distribution of direct normal irradiance. Applied Energy, 303, 117681. 


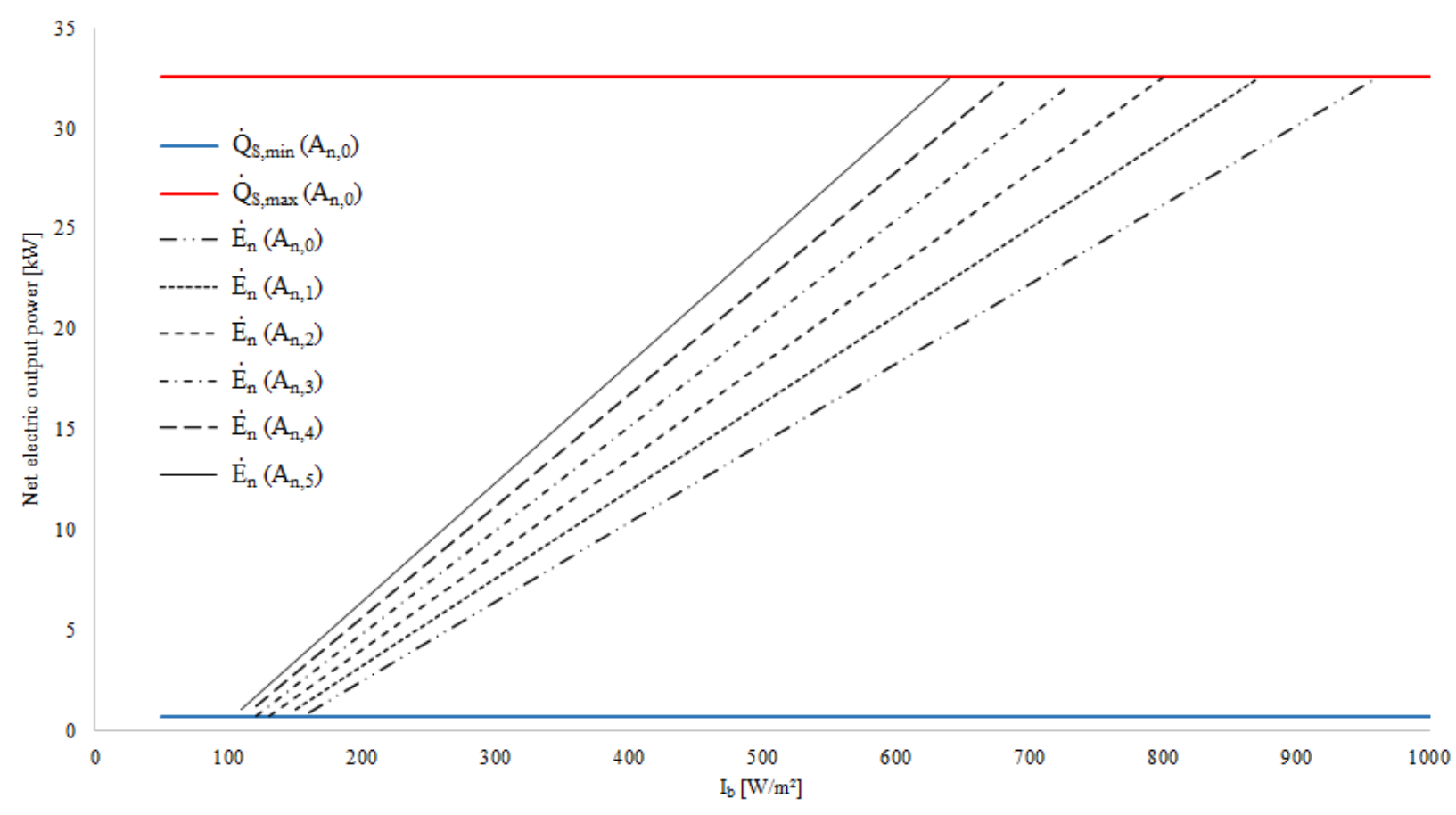

Figure 13: net electric output power of the 6 dish-Stirling configurations as a function of direct normal solar irradiance at $T_{\text {air }}=25\left[{ }^{\circ} \mathrm{C}\right]$ and with clean mirrors

All the curves, in this picture, are limited by a minimum and a maximum power threshold corresponding to the output limits of the actual PCU mounted in the Palermo dish-Stirling plant. From these curves it is evident, as anticipated, that the larger the collector aperture area the lower the solar irradiance corresponding to $I_{b}^{\max }$ (calculated by Eq. 7). Then for each value of $I_{b}$ greater than $I_{b}^{\max }$, the net electrical output power is kept constant through the action of the receiver fan cooler. The results of the numerical simulations in terms of annual net electrical energy production, for all the dish-Stirling configurations and considered locations, calculated using the PVGIS solar input data with the hourly based approach are reported in Tab. 3.

Table 3: annual electric output energy $\left(E_{t}\right)$ for all the 42 examined cases expressed in [MWhe/year]

\begin{tabular}{lcccccc}
\hline Location & $\mathbf{A}_{\mathbf{n}, \mathbf{0}}$ & $\mathbf{A}_{\mathbf{n}, \mathbf{1}}$ & $\mathbf{A}_{\mathbf{n}, \mathbf{2}}$ & $\mathbf{A}_{\mathbf{n}, \mathbf{3}}$ & $\mathbf{A}_{\mathbf{n}, \mathbf{4}}$ & $\mathbf{A}_{\mathbf{n}, \mathbf{5}}$ \\
\hline Brindisi & 44.08 & 50.01 & 55.70 & 60.10 & 63.27 & 65.72 \\
\hline Cagliari & 49.13 & 55.63 & 61.48 & 65.88 & 69.09 & 71.55 \\
\hline
\end{tabular}

Preprint version; Please cite this paper as: Buscemi, A., Guarino, S., Ciulla, G., \& Lo Brano, V. (2021). A methodology for optimisation of solar dish-Stirling systems size, based on the local frequency distribution of direct normal irradiance. Applied Energy, 303, 117681. 


\begin{tabular}{lcccccc}
\hline Lampedusa & 50.2 & 56.95 & 63.21 & 67.90 & 71.38 & 74.08 \\
\hline Naples & 44.32 & 50.25 & 55.60 & 59.66 & 62.62 & 64.89 \\
\hline Palermo & 43.84 & 49.75 & 55.19 & 59.28 & 62.37 & 64.78 \\
\hline Ragusa & 47.85 & 54.27 & 60.32 & 64.72 & 67.96 & 70.46 \\
\hline Rome & 43.47 & 49.31 & 54.67 & 58.74 & 61.77 & 64.12 \\
\hline
\end{tabular}

Comparing Tab. 3 to Tab. 2, it is possible to observe that, for fixed collector configuration, the annual electric production $\left(E_{t}\right)$ is proportional to the annual direct solar irradiation values. Thusanalysed, a linear correlation between the annual net electrical energy collector output and the annual direct solar irradiation emerges for each plant configuration. These functions are represented in Fig. 14 for all configurations ( $A_{\mathrm{n}, 0}, A_{\mathrm{n}, 1}, A_{\mathrm{n}, 2}, A_{\mathrm{n}, 3}, A_{\mathrm{n}, 4}$ and $\left.A_{\mathrm{n}, 5}\right)$ and can be employed to make an initial estimate of the electrical production of a dish-Stirling concentrator as a function of the annual solar irradiation values of the plant installation site.

For example, in the case of the basic configuration of the dish-Stirling system $\left(A_{\mathrm{n}, 0}\right)$, this production varies between about 40 and $50 \mathrm{MWh}_{\mathrm{e}} /$ year corresponding to annual direct solar irradiation values of between 1800 and $2060 \mathrm{kWh} /\left(\mathrm{m}^{2} \cdot\right.$ year $)$.

Preprint version; Please cite this paper as: Buscemi, A., Guarino, S., Ciulla, G., \& Lo Brano, V. (2021). A methodology for optimisation of solar dish-Stirling systems size, based on the local frequency distribution of direct normal irradiance. Applied Energy, 303, 117681. 


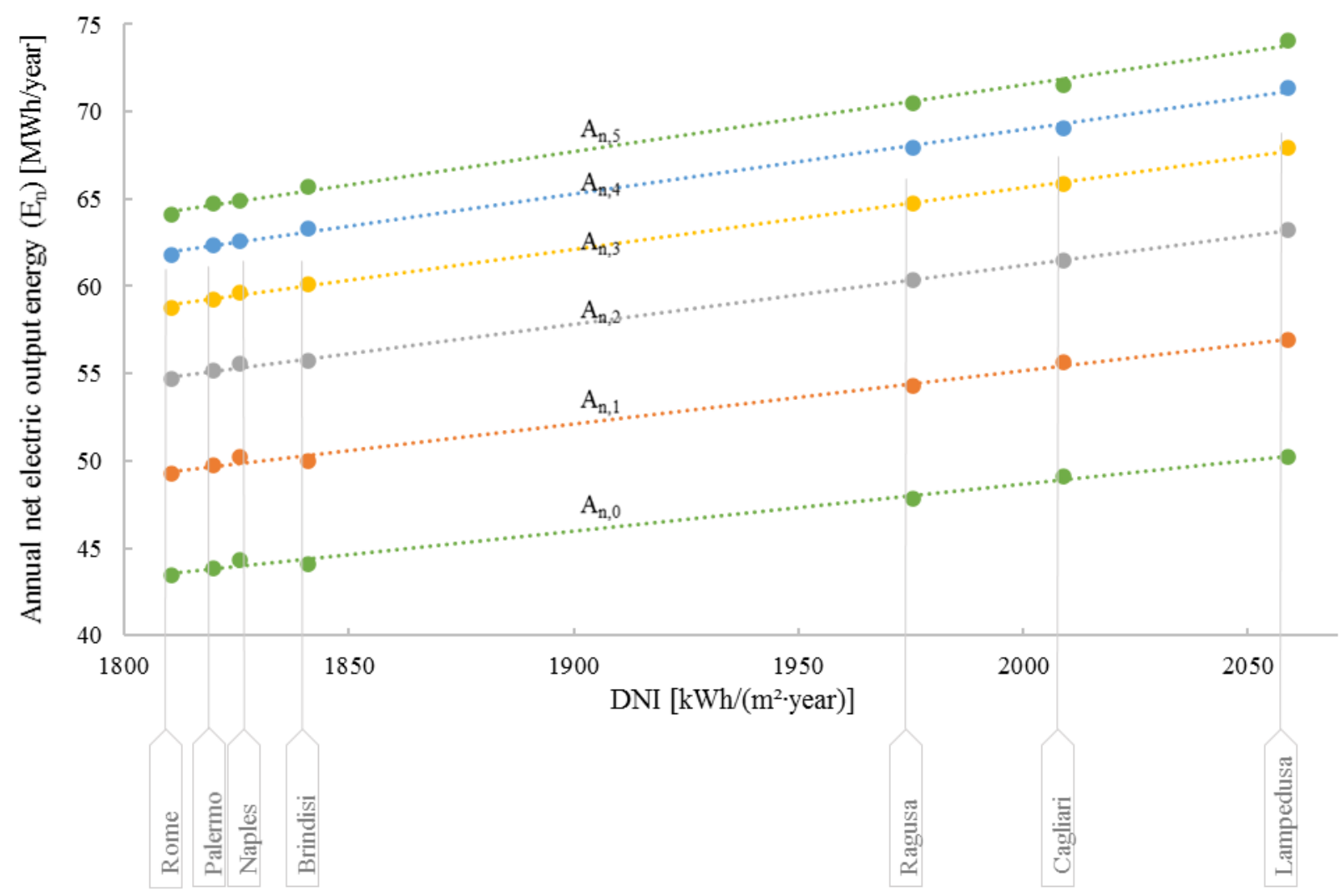

Figure 14: linear correlations of the annual net electric output energy as a function of the annual DNI for different dish-Stirling configurations

On the other hand, independent of plant location, the annual energy production of dish-Stirling concentrators increases with the aperture area of the solar collectors, up to a maximum of about $47 \%$, corresponding to a solar collector with an opening area increase of $50 \%\left(A_{\mathrm{n}, 5}=159 \mathrm{~m}^{2}\right)$. For example, in the case of the most productive site (Lampedusa) among the 7 analysed, $E_{t}$ increases from about 50 to $74 \mathrm{MWh}_{\mathrm{e}}$ year going from the basic configuration to that characterised by the largest collector aperture area as depicted with the blue line in Fig.15. The same figure also shows the trend of the annual efficiency $\bar{\eta}_{\text {sol-ele }}$ calculated for the different configurations located in Lampedusa. From this data, it can be observed that this efficiency increases from a value of $24 \%$ for the basic configuration to a maximum of about $25 \%$ for the $A_{\mathrm{n}, 2}$ configuration and then decreases to about $23 \%$ for the $A_{\mathrm{n}, 5}$ configuration. This interesting observation indicates the possibility of adopting a maximum annual $\bar{\eta}_{\text {sol-ele }}$ efficiency of the system as an optimisation criterion for dish-Stirling systems. Clearly, the maximum $\bar{\eta}_{\text {sol-ele }}$ depends on: technical characteristics of the engine, the aperture area of the reflector

Preprint version; Please cite this paper as: Buscemi, A., Guarino, S., Ciulla, G., \& Lo Brano, V. (2021). A methodology for optimisation of solar dish-Stirling systems size, based on the local frequency distribution of direct normal irradiance. Applied Energy, 303, 117681. 
and the hourly frequency distribution of direct solar radiation characteristics of the installation site. Therefore, for the purposes of the analyses that will be shown below in this work, the optimal configuration for Lampedusa is called $A_{\mathrm{n}, 2}$.

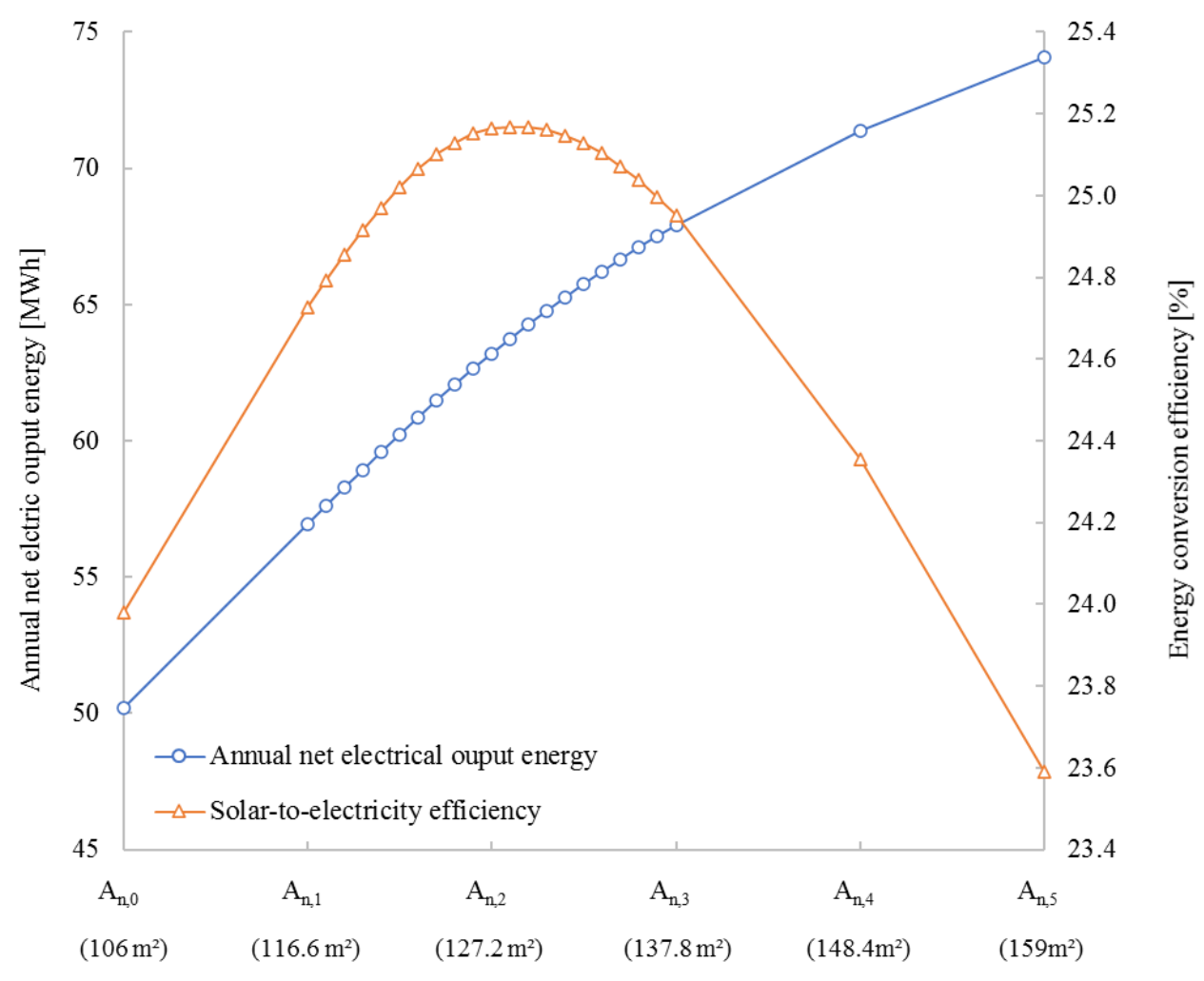

Figure 15: the annual net electricity output and the solar-to-electric conversion efficiency assessed for each of the investigated configurations of the dish-Stirling system located at Lampedusa

Once the energy production values for the different configurations of dish-Stirling concentrators were calculated it was possible to estimate their LCOE values using the expression described by Eq. 12. Lampedusa was considered as the reference location for these analyses, since, among those considered, it is the one characterised by the highest values of annual direct solar irradiation (about $2060 \mathrm{kWh} /\left(\mathrm{m}^{2} \cdot\right.$ year). For a basic collector $\left(A_{\mathrm{n}, 0}\right)$ installed at this location, an LCOE $=0.47 € / \mathrm{kWh}$ was deduced assuming its current installed cost. For the $A_{\mathrm{n}, 2}$ configuration, instead, the LCOE value reduced to $0.37 € / \mathrm{kWh}$, consistent with the fact that this configuration can generate more electric energy in one year (about $E_{t}=63.2 \mathrm{MWh}_{\mathrm{e}} /$ year). The $A_{\mathrm{n}, 2}$ configuration, in fact, can be considered to be optimised for the typical solar radiation conditions of the central Mediterranean, as described above. Assuming then an annual installed cost reduction equal to that of the other CSP

Preprint version; Please cite this paper as: Buscemi, A., Guarino, S., Ciulla, G., \& Lo Brano, V. (2021). A methodology for optimisation of solar dish-Stirling systems size, based on the local frequency distribution of direct normal irradiance. Applied Energy, 303, 117681. 
technologies in the last decade (about $-334 \mathrm{~kW}_{\mathrm{p}} /$ year) it was possible to simulate a feasible trend over time of the LCOE for the same plant configuration and location. The result of this analysis is represented in Fig. 16 along with the global weighted average of LCOE recorded for all the other solar technologies (CSP and PV) in the last decade [11].

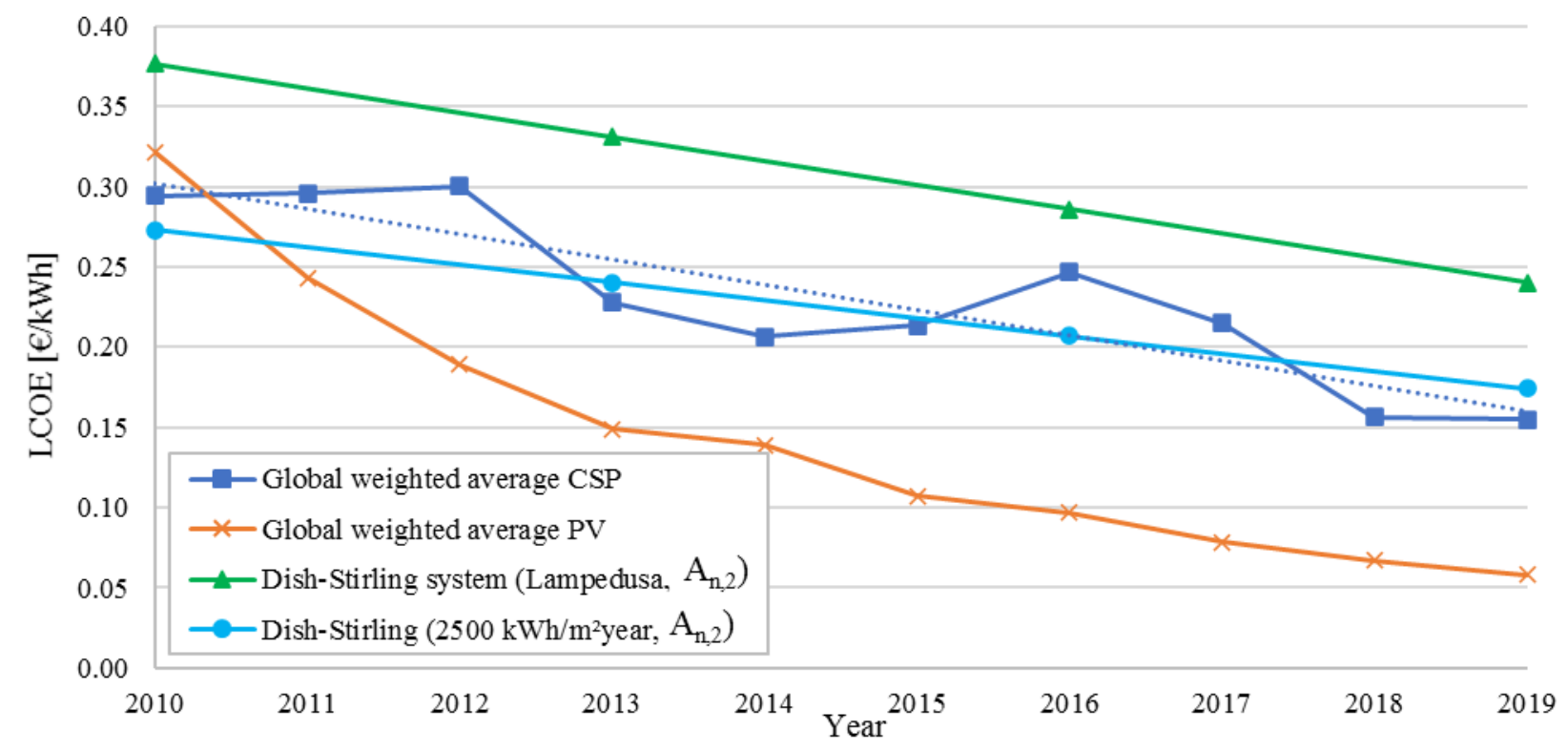

Figure 16: comparison between the LCOE simulated for dish-Stirling systems and the global weighted average LCOE of the others solar technologies recorded between 2010-2019

These results show, for the considered dish-Stirling collector, an LCOE reduction tendency similar to that of the other CSP systems (dotted line in Fig. 16) even though the LCOE values of the dishStirling are always higher than the other systems. In fact, after 10 years the dish-Stirling system of Lampedusa would be characterised by an LCOE $=0.24 € / \mathrm{kWh}$ while for all the other CSP technologies this value is equal to about $\mathrm{LCOE}=0.15 € / \mathrm{kWh}$. The results of this analysis clearly confirm that the area of the Mediterranean investigated in this study is characterised by DNI levels (ranging between $1800-2000 \mathrm{kWh} /\left(\mathrm{m}^{2} \cdot\right.$ year)), which are at the lower limit of those considered of interest for power generation through CSP systems. However, if the same analysis is conducted for a dish-Stirling plant located at a hypothetical geographical position characterised by annual DNI values of about $2500 \mathrm{kWh} /\left(\mathrm{m}^{2} \cdot\right.$ year $)$, similar to those of the sites where CSP plants are typically built, lower values of the LCOE are obtained for dish-Stirling concentrators (see Fig. 16). The electricity production used for this analysis was extrapolated from the linear correlation of Fig. 14 for the $A_{\mathrm{n}, 2}$ configuration corresponding to an annual DNI value of $2500 \mathrm{kWh} /\left(\mathrm{m}^{2} \cdot\right.$ year $)$. The same approach was then repeated considering DNI variables between 2000 and $3000 \mathrm{kWh} /\left(\mathrm{m}^{2} \cdot\right.$ year $)$ and assuming an

Preprint version; Please cite this paper as: Buscemi, A., Guarino, S., Ciulla, G., \& Lo Brano, V. (2021). A methodology for optimisation of solar dish-Stirling systems size, based on the local frequency distribution of direct normal irradiance. Applied Energy, 303, 117681. 
installed cost of the $A_{\mathrm{n}, 2}$ configuration corresponding to that of the tenth year. The result of this calculation, plotted in Fig. 17, shows an interesting outcome of this study: if the dish-Stirling systems, with optimised collector extensions, are realised in large numbers in geographical zones characterised by annual DNI values of between 2400 and $2700 \mathrm{kWh} /\left(\mathrm{m}^{2} \cdot\right.$ year $)$, the expected currently value of the LCOE of this technology would conform to that of other CSP systems.

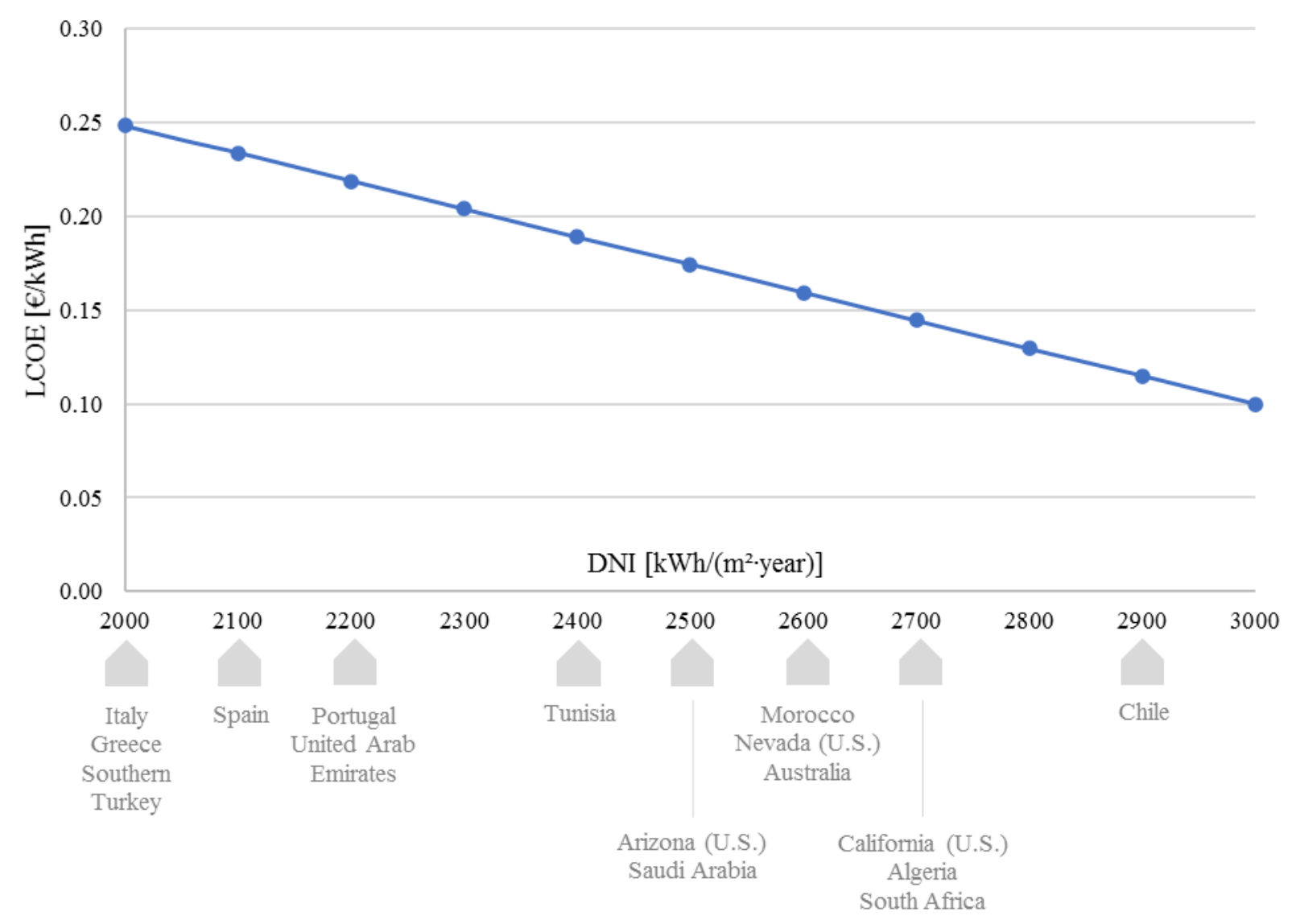

Figure 17: LCOE variations as a function of the DNI levels for $A_{\mathrm{n}, 3}$ configuration considering the installed cost assumed at the tenth year

Furthermore, assuming the same $I_{0}^{(\mathrm{i})}$ function already hypothesised for the LCOE analyses and considering the $E_{t}$ of the 42 plants in Tab. 3, the new incentive scheme proposed in this study was verified. For each of these cases, in fact, the yearly variation of the feed-in tariff $T_{\text {feed-in }}^{(\mathrm{i})}$ was calculated using the expression described by Eq. 16. These functions were then averaged to define a single regional feed-in tariff function. This function represents the variations of the feed-in tariffs dedicated to plants falling under the incentive plan at the $i$-th calendar year after its entry into force.

Preprint version; Please cite this paper as: Buscemi, A., Guarino, S., Ciulla, G., \& Lo Brano, V. (2021). A methodology for optimisation of solar dish-Stirling systems size, based on the local frequency distribution of direct normal irradiance. Applied Energy, 303, 117681. 
The result of these calculations (plotted in Fig. 18) show that the average tariff varies linearly passing from an initial value of $T_{\text {feed-in }}^{(0)}=0.46 € / \mathrm{kWh}$ to a final value of $T_{\text {feed-in }}^{(9)}=0.27 € / \mathrm{kWh}$. By using this function, the DPBT of each of the 42 cases was calculated using Eq. 14 and the main hypothesis of the proposed incentive scheme was verified, that is: the 42 DPBT values of Tab. 4 remain, with a good approximation, constant regardless of the calendar year in which each plant is admitted to the incentive plan.

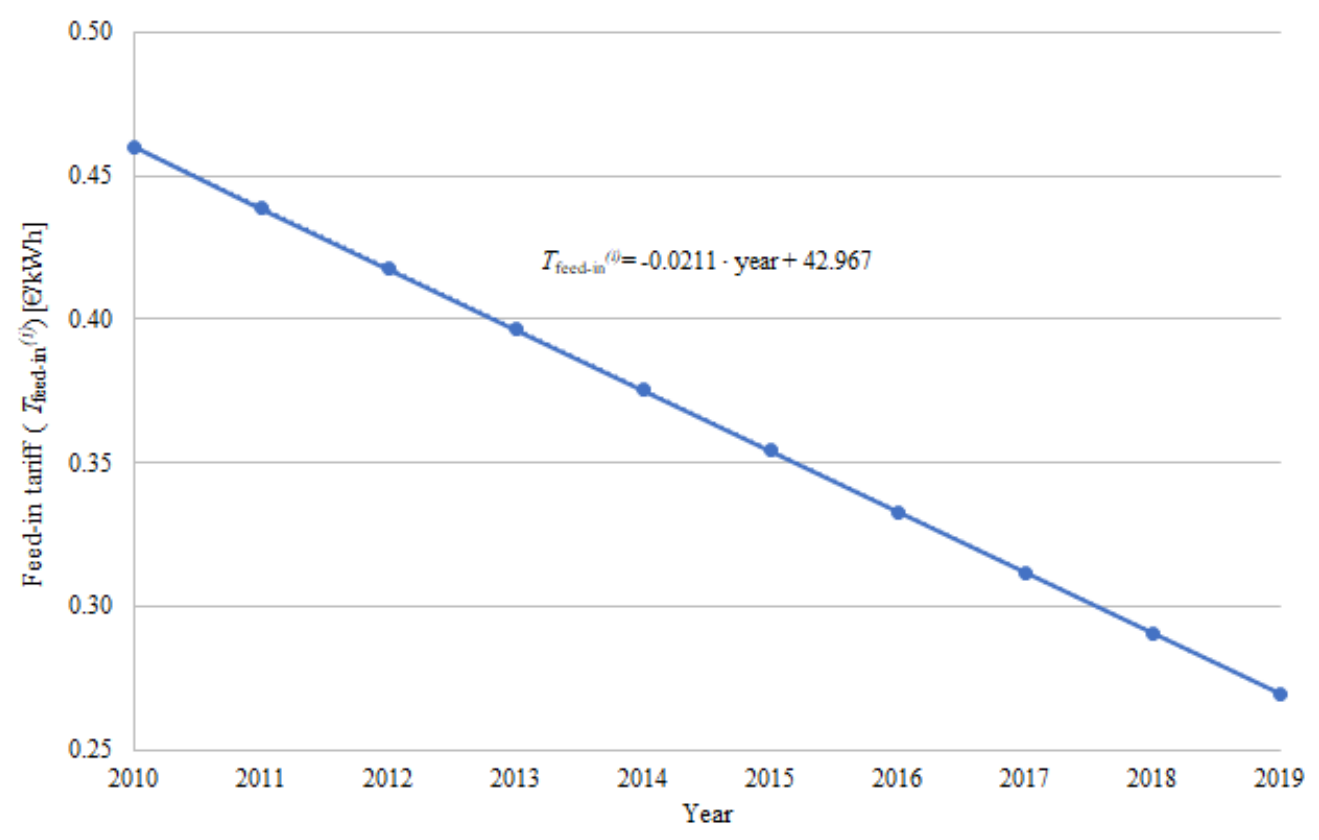

Figure 18: feed-in tariff variation over 10 years according to the proposed incentive scheme

These DPBT values reported in Tab. 4 for all the analysed cases, show that the optimised dish-Stirling configuration $\left(A_{\mathrm{n}, 2}\right)$ installed at the most productive location (e.g. Lampedusa) present DPBT values ranging around 15 years.

Table 4: DPBT values calculated for the 42 analysed cases

\begin{tabular}{ccccccc}
\hline DPBT $^{(\mathbf{1})}$ & $\mathbf{A}_{\mathbf{n}, \mathbf{0}}$ & $\mathbf{A}_{\mathbf{n}, \mathbf{1}}$ & $\mathbf{A}_{\mathbf{n}, \mathbf{2}}$ & $\mathbf{A}_{\mathbf{n}, \mathbf{3}}$ & $\mathbf{A}_{\mathbf{n}, \mathbf{4}}$ & $\mathbf{A}_{\mathbf{n}, \mathbf{5}}$ \\
\hline Brindisi & 28.9 & 20.0 & 15.8 & 13.8 & 12.7 & 12.1 \\
\hline Cagliari & 20.5 & 15.5 & 12.9 & 11.6 & 10.9 & 10.4 \\
\hline Lampedusa & 19.3 & 14.8 & 12.4 & 11.1 & 10.3 & 9.9 \\
\hline Naples & 28.3 & 19.7 & 15.9 & 14.0 & 13.0 & 12.4 \\
\hline
\end{tabular}

Preprint version; Please cite this paper as: Buscemi, A., Guarino, S., Ciulla, G., \& Lo Brano, V. (2021). A methodology for optimisation of solar dish-Stirling systems size, based on the local frequency distribution of direct normal irradiance. Applied Energy, 303, 117681. 


\begin{tabular}{ccccccc}
\hline Palermo & 29.6 & 20.2 & 16.1 & 14.2 & 13.1 & 12.4 \\
\hline Ragusa & 22.0 & 16.4 & 13.5 & 12.0 & 11.2 & 10.7 \\
\hline Rome & 30.7 & 20.7 & 16.5 & 14.4 & 13.3 & 12.6 \\
\hline DPBT $^{(\mathbf{1 0 )}}$ & $\mathbf{A}_{\mathbf{n}, \mathbf{0}}$ & $\mathbf{A}_{\mathbf{n}, \mathbf{1}}$ & $\mathbf{A}_{\mathbf{n}, \mathbf{2}}$ & $\mathbf{A}_{\mathbf{n}, \mathbf{3}}$ & $\mathbf{A}_{\mathbf{n}, \mathbf{4}}$ & $\mathbf{A}_{\mathbf{n}, \mathbf{5}}$ \\
\hline Brindisi & 30.6 & 20.2 & 15.8 & 13.8 & 12.8 & 12.2 \\
\hline Cagliari & 20.4 & 15.3 & 12.8 & 11.5 & 10.8 & 10.4 \\
\hline Lampedusa & 19.1 & 14.5 & 12.1 & 10.8 & 10.2 & 9.8 \\
\hline Naples & 29.8 & 19.9 & 15.9 & 14.0 & 13.0 & 12.5 \\
\hline Palermo & 31.4 & 20.5 & 16.2 & 14.2 & 13.2 & 12.5 \\
\hline Ragusa & 22.1 & 16.2 & 13.3 & 11.9 & 11.1 & 10.7 \\
\hline Rome & 32.9 & 21.1 & 16.5 & 14.5 & 13.4 & 12.8 \\
\hline
\end{tabular}

Finally, by means of Eq. 13, the NPV values were calculated for all cases, considering their variations in the first ten years. The NPV values relative to the first and tenth year are shown for comparison in Tab. 5. These results show that the profitability of investments in plants falling under the incentive scheme in the tenth year since its entry into force is almost halved compared to those of plants incentivised since the first year.

Table 5: NPV values of the 42 analysed cases calculated at the first and tenth year since the entry into force of the incentives

\begin{tabular}{ccccccc}
\hline NPV $^{(\mathbf{1})}$ & $\mathbf{A}_{\mathbf{n}, \mathbf{0}}$ & $\mathbf{A}_{\mathbf{n}, \mathbf{1}}$ & $\mathbf{A}_{\mathbf{n}, \mathbf{2}}$ & $\mathbf{A}_{\mathbf{n}, \mathbf{3}}$ & $\mathbf{A}_{\mathbf{n}, \mathbf{4}}$ & $\mathbf{A}_{\mathbf{n}, \mathbf{5}}$ \\
\hline Brindisi & $-€ 8,613$ & $€ 17,768$ & $€ 43,098$ & $€ 62,207$ & $€ 75,508$ & $€ 85,322$ \\
\hline Cagliari & $€ 15,499$ & $€ 44,607$ & $€ 70,689$ & $€ 89,793$ & $€ 103,229$ & $€ 113,136$ \\
\hline Lampedusa & $€ 20,598$ & $€ 50,872$ & $€ 78,937$ & $€ 99,429$ & $€ 114,170$ & $€ 125,170$ \\
\hline Naples & $-€ 7,453$ & $€ 18,871$ & $€ 42,633$ & $€ 60,103$ & $€ 72,396$ & $€ 81,340$ \\
\hline Palermo & $-€ 9,752$ & $€ 16,482$ & $€ 40,665$ & $€ 58,313$ & $€ 71,191$ & $€ 80,826$ \\
\hline Ragusa & $€ 9,404$ & $€ 38,195$ & $€ 65,138$ & $€ 84,279$ & $€ 97,846$ & $€ 107,912$ \\
\hline Rome & $-€ 10,225$ & $€ 11,905$ & $€ 32,117$ & $€ 47,013$ & $€ 57,613$ & $€ 65,435$ \\
\hline NPV (10) & $\mathbf{A}_{\mathbf{n}, \mathbf{0}}$ & $\mathbf{\mathbf { A } _ { \mathbf { n } , \mathbf { 1 } }}$ & $\mathbf{\mathbf { A } _ { \mathbf { n } , \mathbf { 2 } }}$ & $\mathbf{\mathbf { A } _ { \mathbf { n } , \mathbf { 3 } }}$ & $\mathbf{\mathbf { A } _ { \mathbf { n } , 4 }}$ & $\mathbf{A}_{\mathbf{n}, \mathbf{5}}$ \\
\hline Brindisi & $-€ 5,932$ & $€ 8,801$ & $€ 22,916$ & $€ 33,377$ & $€ 40,424$ & $€ 45,423$ \\
\hline
\end{tabular}

Preprint version; Please cite this paper as: Buscemi, A., Guarino, S., Ciulla, G., \& Lo Brano, V. (2021). A methodology for optimisation of solar dish-Stirling systems size, based on the local frequency distribution of direct normal irradiance. Applied Energy, 303, 117681. 


\begin{tabular}{crrrrrr}
\hline Cagliari & $€ 8,235$ & $€ 24,570$ & $€ 39,127$ & $€ 49,585$ & $€ 56,711$ & $€ 61,765$ \\
\hline Lampedusa & $€ 11,231$ & $€ 28,251$ & $€ 43,973$ & $€ 55,246$ & $€ 63,140$ & $€ 68,836$ \\
\hline Naples & $-€ 5,251$ & $€ 9,449$ & $€ 22,643$ & $€ 32,140$ & $€ 38,596$ & $€ 43,083$ \\
\hline Palermo & $-€ 6,602$ & $€ 8,045$ & $€ 21,486$ & $€ 31,088$ & $€ 37,888$ & $€ 42,781$ \\
\hline Ragusa & $€ 4,654$ & $€ 20,802$ & $€ 35,866$ & $€ 46,345$ & $€ 53,549$ & $€ 58,696$ \\
\hline Rome & $-€ 7,640$ & $€ 6,842$ & $€ 20,018$ & $€ 29,571$ & $€ 36,199$ & $€ 40,934$ \\
\hline
\end{tabular}

Moreover, as indicated by the negative NPV values in Tab. 5, the investment in the basic configuration of the dish-Stirling $A_{\mathrm{n} .0}$ collector (which is the one currently operating in Palermo) would not be profitable, from a financial point of view, not even for plants falling under the first year of incentives.

\section{CONCLUSIONS}

The annual solar-to-electric conversion efficiency of dish-Stirling systems can be increased by optimizing the size of the collector aperture area to the hourly frequency distributions of direct normal irradiance typical of the installation site. With this work, a new energy model of the dish-Stirling concentrator capable of carrying out this kind of optimization analysis is presented. The numerical model, calibrated with the real operating data of a $32 \mathrm{~kW}_{\mathrm{p}}$ dish-Stirling system located in Palermo (Italy), was used to assess the annual energy production of six different plant configurations at seven different locations in the central Mediterranean. In this geographical area the annual direct solar irradiation varies between 1800 and $2060 \mathrm{kWh} /\left(\mathrm{m}^{2} \cdot\right.$ year $)$ with annual hourly frequency peaks of about 750 hours at DNI classes of between 700 and $800 \mathrm{~W} / \mathrm{m}^{2}$. The results of the numerical simulations show that the current dish-Stirling configuration presents an average annual solar-to-electric conversion efficiency of $24 \%$, being able to produce between 40 and $50 \mathrm{MWh}_{\mathrm{e}} /$ year of electricity at the typical direct normal irradiance range at the analysed locations. On the other hand, an optimised configuration of the collector, designed by expanding the collector opening area by $20 \%$ to allow a peak power output of the Stirling engine at $\mathrm{DNI}=700-800 \mathrm{~W} / \mathrm{m}^{2}$, can increase the energy production by about $26 \%$ at the most productive site. This configuration, which could be implemented with a modest increase in the installed costs, can also permit a reduction of the current estimated Levelized Cost of Energy of this technology from 0.47 to $0.37 € / \mathrm{kWh}$. The latter value of Levelized Cost of Energy would be further reduced to $0.24 € / \mathrm{kWh}$ after 10 years if it is assumed that the installed cost reduction trend is similar to that of other concentrating solar power systems in the last decade (about

Preprint version; Please cite this paper as: Buscemi, A., Guarino, S., Ciulla, G., \& Lo Brano, V. (2021). A methodology for optimisation of solar dish-Stirling systems size, based on the local frequency distribution of direct normal irradiance. Applied Energy, 303, 117681. 
$-334 \mathrm{~kW}_{\mathrm{p}}$ /year). Interestingly, repeating the latter analysis for a geographical location with annual direct normal irradiation values similar to those of the zones where large concentrating solar power systems are typically built, results in an Levelized Cost of Energy of $0.17 € / \mathrm{kWh}$ which is a value close to the current one of all the other concentrating solar power systems. In the analyses above, it is assumed that the reduction over time of installed costs of dish-Stirling systems is due to the effect of economies of scale triggered by a greater diffusion of these systems in the concentrating solar power generation market. To this end, a new incentive scheme dedicated to dish-Stirling plants is also proposed, structured so as to have a feed-in tariff that varies according to the year in which the plant falls under the incentive scheme and designed to guarantee that the discounted payback time of the investments is constant regardless of the year the plant is built. The proposed scheme was tested considering the energy production calculated for solar collectors in the central Mediterranean, demonstrating that it would be possible to obtain discounted payback time values around 10 years for the optimised plant configuration located in the most productive site. This scheme is characterised by a regional feed-in tariff variable from $0.46 € / \mathrm{kWh}$ in the first year to $0.27 € / \mathrm{kWh}$ in the tenth.

In future research, the analyses presented in this paper for dish-Stirling systems could be extended and specialised to geographical locations with direct normal irradiance levels higher than those in the central Mediterranean. With this aim, the new simplified calculation method that was developed with this work can be used. This method allows the simulation of the annual electricity production of a dish-Stirling system from the frequency histograms of 1-hour direct normal irradiance series. This new approach may also be used for the optimization of dish-Stirling systems using direct normal irradiance hourly frequency distributions that are generated through suitable statistical methods for a macro-climatic area.

\title{
NOMENCLATURE
}

$a_{1} \quad$ first parameter of the Stirling engine mechanical efficiency curve [-]

$a_{2} \quad$ second parameter of the Stirling engine mechanical efficiency curve [W]

$A_{n} \quad$ net effective aperture area of the reflector $\left[\mathrm{m}^{2}\right]$

$A_{n, i} \quad$ net effective aperture area of the reflector for the i-th configuration of 6 (i ranges

\author{
from 0 to 5) $\left[\mathrm{m}^{2}\right]$ \\ $A_{r} \quad$ receiver aperture area $\left[\mathrm{m}^{2}\right]$ \\ $C F_{t} \quad$ cash flow of the $t$-th year of the lifetime of the project [€]
}

Preprint version; Please cite this paper as: Buscemi, A., Guarino, S., Ciulla, G., \& Lo Brano, V. (2021). A methodology for optimisation of solar dish-Stirling systems size, based on the local frequency distribution of direct normal irradiance. Applied Energy, 303, 117681. 
$D N I_{e} \quad$ the annual effective direct solar irradiation $\left[\mathrm{kWh} /\left(\mathrm{m}^{2} \cdot \mathrm{year}\right)\right]$

$\dot{E}_{n} \quad$ net electric output power produced by a dish-Stirling system [W]

$\left(\dot{E}_{n}\right)_{h o r} \quad$ net electric power produced by the dish-Stirling system calculated by the hourlybased approach [W]

$\dot{E}_{p}^{a v e} \quad$ average value of the parasitic plant consumption [W]

$E_{s} \quad$ solar direct normal energy corresponding to each $I_{b}$ bin $\left[\mathrm{kWh} / \mathrm{m}^{2}\right]$

$E_{t} \quad$ amount of electricity produced in the year $t$-th $[\mathrm{kWh}]$

$\left(E_{t}\right)_{\text {hor }} \quad$ electricity produced in the year $t$-th calculated by the hourly-based approach [kWh]

$\left(\bar{E}_{t}\right)_{h o r} \quad$ annual average electricity calculated by the hourly-based approach [kWh]

$\left(E_{t}\right)_{\text {sim }} \quad$ electricity produced in the year $t$-th calculated by the simplified approach [kWh]

$\left(\bar{E}_{t}\right)_{\text {sim }} \quad$ annual average electricity calculated by the simplified approach $[\mathrm{kWh}]$

$\left(\dot{E}_{t}\right)_{\text {sim }} \quad$ average electric power output calculated according to the simplified approach [kWh]

$F_{t} \quad$ fossil fuel cost $[€]$

$h_{r} \quad$ receiver convective coefficient $\left[\mathrm{W} /\left(\mathrm{m}^{2} \cdot \mathrm{K}\right)\right]$

$i \quad i$-th year since the beginning of the incentive plan

$I_{b} \quad$ solar beam irradiance $\left[\mathrm{W} / \mathrm{m}^{2}\right]$

$\bar{I}_{b} \quad$ the middle-point value of the $I_{b}$ bin $\left[\mathrm{W} / \mathrm{m}^{2}\right]$

$I_{b}^{\max } \quad$ upper limit of the direct solar irradiance $\left[\mathrm{W} / \mathrm{m}^{2}\right]$

$I_{b}^{\min } \quad$ lower limit of the direct solar irradiance $\left[\mathrm{W} / \mathrm{m}^{2}\right]$

$I_{t} \quad$ investment cost that occurs in the year $\mathrm{t}[€]$

$M_{t} \quad$ operation maintenance cost that occurs in the year $\mathrm{t}[€]$

$N \quad$ number of years of the time series of solar data [year]

$n \quad$ lifetime of the power plant under consideration [year]

$n_{I_{b}} \quad$ number of cases falling into each $I_{b}$ bin $[\mathrm{h}]$

$\bar{n}_{I_{b}} \quad$ annual average values of $n_{I_{b}}[\mathrm{~h}]$

Preprint version; Please cite this paper as: Buscemi, A., Guarino, S., Ciulla, G., \& Lo Brano, V. (2021). A methodology for optimisation of solar dish-Stirling systems size, based on the local frequency distribution of direct normal irradiance. Applied Energy, 303, 117681. 


\begin{tabular}{|c|c|}
\hline$P_{\mathrm{r}, \text { solar }}$ & bonus for integrated solar plant $\left[€ / \mathrm{kWh}_{\mathrm{e}}\right]$ \\
\hline$\dot{Q}_{r e j}$ & heat power rejected from the receiver by a cooling fan $[\mathrm{W}]$ \\
\hline$\dot{Q}_{r, \text { out }}$ & heat loss power from the receiver $[\mathrm{W}]$ \\
\hline$\dot{Q}_{S, i n}$ & thermal input power of the Stirling engine [W] \\
\hline$\dot{Q}_{S, \text { in }}^{\max }$ & upper limit of the thermal input power of the Stirling engine [W] \\
\hline$\dot{Q}_{S, i n}^{\min }$ & lower limit of the thermal input power of the Stirling engine [W] \\
\hline$r$ & interest rate used for discounting expenditures and revenues [-] \\
\hline$R_{T}$ & temperature correction factor [-] \\
\hline$t$ & $t$-th year of the lifetime of the power plant \\
\hline$T_{0}$ & reference temperature $\left[{ }^{\circ} \mathrm{C}\right]$ \\
\hline$T_{\text {air }}$ & air temperature $\left[{ }^{\circ} \mathrm{C}\right]$ \\
\hline $\bar{T}_{\text {air }}$ & average air temperature of each $I_{b}$ bin $\left[{ }^{\circ} \mathrm{C}\right]$ \\
\hline$T_{\mathrm{b}}$ & base incentive tariff $\left[€ / \mathrm{kWh}_{\mathrm{e}}\right]$ \\
\hline$T_{\text {feed-in }}^{(i)}$ & feed-in tariff $\left[€ / \mathrm{kWh}_{\mathrm{e}}\right]$ \\
\hline$T_{r}^{a v e}$ & average receiver temperature $\left[{ }^{\circ} \mathrm{C}\right]$ \\
\hline$T_{s k y}$ & apparent sky temperature $\left[{ }^{\circ} \mathrm{C}\right]$ \\
\hline$\dot{W}_{S}$ & mechanical output power of the Stirling engine [W] \\
\hline
\end{tabular}

Greek letters
$\Delta I_{b} \quad$ width of each $I_{b}$ bin $\left[\mathrm{W} / \mathrm{m}^{2}\right]$
$\varepsilon_{r} \quad$ the effective emissivity of the receiver [-]
$\eta_{o} \quad$ the optical efficiency of the system [-]
$\eta_{c l e} \quad$ the cleanliness index of the collector mirrors [-]
$\eta_{c l e}^{\text {ave }} \quad$ the average cleanliness index of the collector mirrors [-]
$\eta_{e} \quad$ the electric efficiency of the alternator [-]
$\eta_{\text {sol-ele }} \quad$ the instantaneous solar-to-electric energy conversion efficiency [-]

Preprint version; Please cite this paper as: Buscemi, A., Guarino, S., Ciulla, G., \& Lo Brano, V. (2021). A methodology for optimisation of solar dish-Stirling systems size, based on the local frequency distribution of direct normal irradiance. Applied Energy, 303, 117681. 

$\bar{\eta}_{\text {sol-ele }}$
the annual solar-to-electric energy conversion efficiency [-]
$\sigma$
the Stefan-Boltzmann constant $\left[\mathrm{W} /\left(\mathrm{m}^{2} \cdot \mathrm{K}^{4}\right)\right]$

Acronyms

$\begin{array}{ll}\mathrm{CO}_{2} & \text { Carbon dioxide } \\ \text { CSP } & \text { Concentrating Solar Power } \\ \text { DNI } & \text { Direct Normal Irradiance }\left[\mathrm{W} / \mathrm{m}^{2}\right] \\ \text { DPBT } & \text { Discounted Payback Time }[\text { year }] \\ \text { GHG } & \text { Greenhouse Gases } \\ \text { LCOE } & \text { Levelized Costs of Electricity }[€ / \mathrm{kWh}] \\ \text { NPV } & \text { Net Present Value }[€] \\ \text { NREL } & \text { National Renewable Energy Laboratory } \\ \text { OECD } & \text { Organisation for Economic Co-operation and Development } \\ \text { PCU } & \text { Power Conversion Unit } \\ \text { PV } & \text { Photovoltaic } \\ \text { PVGIS } & \text { Photovoltaic Geographical Information System } \\ \text { SBP } & \text { Schlaich Bergermann und Partner } \\ \text { TMY } & \text { Typical Meteorological Year }\end{array}$

\section{ACKNOWLEDGEMENTS}

The authors express gratitude to the companies HorizonFirm S.r.1., Elettrocostruzioni S.r.1. and Ripasso Energy for the support provided without which it would not have been possible to install the dish-Stirling concentrator plant at the University of Palermo campus.

Preprint version; Please cite this paper as: Buscemi, A., Guarino, S., Ciulla, G., \& Lo Brano, V. (2021). A methodology for optimisation of solar dish-Stirling systems size, based on the local frequency distribution of direct normal irradiance. Applied Energy, 303, 117681. 


\section{REFERENCES}

[1] González-Roubaud E, Pérez-Osorio D, Prieto C. Review of commercial thermal energy storage in concentrated solar power plants: Steam vs. molten salts. Renew Sustain Energy Rev 2017;80:133-48. https://doi.org/https://doi.org/10.1016/j.rser.2017.05.084.

[2] IEA. Global CO2 emissions in 2019 2020. https://www.iea.org/articles/global-co2emissions-in-2019.

[3] Khan J, Arsalan MH. Solar power technologies for sustainable electricity generation - A review. Renew Sustain Energy Rev 2016;55:414-25. https://doi.org/https://doi.org/10.1016/j.rser.2015.10.135.

[4] Nastasi B, Mazzoni S, Groppi D, Romegnoli A, Garcia DA. Solar Power-To-Gas application to an Island Energy System. Renew Energy 2020.

[5] Pazheri FR, Othman MF, Malik NH. A review on global renewable electricity scenario. Renew Sustain Energy Rev 2014;31:835-45. https://doi.org/https://doi.org/10.1016/j.rser.2013.12.020.

[6] Blanc P, Espinar B, Geuder N, Gueymard C, Meyer R, Pitz-Paal R, et al. Direct normal irradiance related definitions and applications: The circumsolar issue. Sol Energy 2014;110:561-77. https://doi.org/https://doi.org/10.1016/j.solener.2014.10.001.

[7] Lovegrove K, Stein W. Concentrating Solar Power Technology: Principles, Developments and Applications. Woodhead Publushing; 2012. https://doi.org/10.1533/9780857096173.

[8] Coventry J, Andraka C. Dish systems for CSP. Sol Energy 2017;152:140-70. https://doi.org/10.1016/J.SOLENER.2017.02.056.

[9] NREL. National Renewable Energy Laboratory. Concentrating Solar Power Projects with Operational Plants n.d. https://solarpaces.nrel.gov/ (accessed July 17, 2020).

[10] Hernández-Moro J, Martínez-Duart JM. Analytical model for solar PV and CSP electricity costs: Present LCOE values and their future evolution. Renew Sustain Energy Rev 2013;20:119-32. https://doi.org/https://doi.org/10.1016/j.rser.2012.11.082.

[11] IRENA (2020). Renewable Power Generation Costs in 2019. International Renewable Energy Agency, Abu Dhabi.: n.d.

[12] Thombare DG, Verma SK. Technological development in the Stirling cycle engines. Renew Sustain Energy Rev 2008. https://doi.org/10.1016/j.rser.2006.07.001.

[13] Zhang HL, Baeyens J, Degrève J, Cacères G. Concentrated solar power plants: Review and design methodology. Renew Sustain Energy Rev 2013;22:466-81.

Preprint version; Please cite this paper as: Buscemi, A., Guarino, S., Ciulla, G., \& Lo Brano, V. (2021). A methodology for optimisation of solar dish-Stirling systems size, based on the local frequency distribution of direct normal irradiance. Applied Energy, 303, 117681. 
https://doi.org/10.1016/j.rser.2013.01.032.

[14] Sharma A, Shukla SK, Rai AK. Finite time thermodynamic analysis and optimization of solar-dish Stirling heat engine with regenerative losses. Therm Sci 2011;15:995-1009. https://doi.org/10.2298/TSCI110418101S.

[15] Singh UR, Kumar A. Review on solar Stirling engine: Development and performance. Therm Sci Eng Prog 2018;8:244-56. https://doi.org/10.1016/j.tsep.2018.08.016.

[16] Ferreira AC, Nunes ML, Teixeira JCF, Martins LASB, Teixeira SFCF. Thermodynamic and economic optimization of a solar-powered Stirling engine for micro-cogeneration purposes. Energy 2016;111:1-17. https://doi.org/10.1016/j.energy.2016.05.091.

[17] Moghadam RS, Sayyaadi H, Hosseinzade H. Sizing a solar dish Stirling micro-CHP system for residential application in diverse climatic conditions based on 3E analysis. Energy Convers Manag 2013;75:348-65. https://doi.org/10.1016/j.enconman.2013.06.008.

[18] Guarino S, Catrini P, Buscemi A, Lo Brano V, Piacentino A. Assessing the Energy-Saving Potential of a Dish-Stirling Con-Centrator Integrated Into Energy Plants in the Tertiary Sector. Energies 2021;14. https://doi.org/10.3390/en14041163.

[19] Kadri Y, Hadj Abdallah H. Performance evaluation of a stand-alone solar dish Stirling system for power generation suitable for off-grid rural electrification. Energy Convers Manag 2016;129:140-56. https://doi.org/10.1016/j.enconman.2016.10.024.

[20] Al-Dafaie AMA, Dahdolan ME, Al-Nimr MA. Utilizing the heat rejected from a solar dish Stirling engine in potable water production. Sol Energy 2016;136:317-26. https://doi.org/10.1016/j.solener.2016.07.007.

[21] Bumataria RK, Patel NK. Review of Stirling Engines for Pumping Water using Solar Energy as a source of Power. Int J Eng Res Appl 2013;3:864-8.

[22] Monné C, Bravo Y, Moreno F, Muñoz M. Analysis of a solar dish-Stirling system with hybridization and thermal storage. Int J Energy Environ Eng 2014;5:1-5. https://doi.org/10.1007/s40095-014-0080-x.

[23] Su B, Han W, Zhang X, Chen Y, Wang Z, Jin H. Assessment of a combined cooling, heating and power system by synthetic use of biogas and solar energy. Appl Energy 2018;229:92235. https://doi.org/https://doi.org/10.1016/j.apenergy.2018.08.037.

[24] Andraka CE. Dish Stirling advanced latent storage feasibility. Energy Procedia 2014;49:68493. https://doi.org/10.1016/j.egypro.2014.03.074.

[25] Desideri U, Campana PE. Analysis and comparison between a concentrating solar and a

Preprint version; Please cite this paper as: Buscemi, A., Guarino, S., Ciulla, G., \& Lo Brano, V. (2021). A methodology for optimisation of solar dish-Stirling systems size, based on the local frequency distribution of direct normal irradiance. Applied Energy, 303, 117681. 
photovoltaic power plant. Appl Energy 2014;113:422-33.

https://doi.org/https://doi.org/10.1016/j.apenergy.2013.07.046.

[26] Janjai S, Laksanaboonsong J, Seesaard T. Potential application of concentrating solar power systems for the generation of electricity in Thailand. Appl Energy 2011;88:4960-7. https://doi.org/https://doi.org/10.1016/j.apenergy.2011.06.044.

[27] Heller P, Baumüller A, Schiel W. Eurodish the next milestone to decrease the costs of Dish/Stirling System towards competitiveness. Sol Paces Symp Sydney 2000:2-7.

[28] Keck T, Schiel W. EnviroDish and EuroDish System and Status. Proc. ISES Sol. world Congr., 2003.

[29] Mancini T, Heller P, Butler B, Osborn B, Schiel W, Goldberg V, et al. Dish-stirling systems: An overview of development and status. J Sol Energy Eng Trans ASME 2003;125:135-51. https://doi.org/10.1115/1.1562634.

[30] Chaves-Avila JP, Banez-Chicharro F, Ramos A. Impact of support schemes and market rules on renewable electricity generation and system operation: The Spanish case. IET Renew Power Gener 2017;11:238-44. https://doi.org/10.1049/iet-rpg.2016.0246.

[31] Izquierdo S, Montanes C, Dopazo C, Fueyo N. Analysis of CSP plants for the definition of energy policies: The influence on electricity cost of solar multiples, capacity factors and energy storage. Energy Policy 2010;38:6215-21.

[32] European Commission. Roadmap 2050. Policy 2012:1-9. https://doi.org/10.2833/10759.

[33] Guarino S, Buscemi A, Ciulla G, Bonomolo M, Lo Brano V. A dish-stirling solar concentrator coupled to a seasonal thermal energy storage system in the southern mediterranean basin: A cogenerative layout hypothesis. Energy Convers Manag 2020;222:113228. https://doi.org/https://doi.org/10.1016/j.enconman.2020.113228.

[34] Hernández-Moro J, Martínez-Duart JM. CSP electricity cost evolution and grid parities based on the IEA roadmaps. Energy Policy 2012;41:184-92. https://doi.org/10.1016/j.enpol.2011.10.032.

[35] Buscemi A, Lo Brano V, Chiaruzzi C, Ciulla G, Kalogeri C. A validated energy model of a solar dish-Stirling system considering the cleanliness of mirrors. Appl Energy 2020. https://doi.org/10.1016/j.apenergy.2019.114378.

[36] Hafez AZ, Soliman A, El-Metwally KA, Ismail IM. Solar parabolic dish Stirling engine system design, simulation, and thermal analysis. Energy Convers Manag 2016;126:60-75. https://doi.org/10.1016/j.enconman.2016.07.067.

Preprint version; Please cite this paper as: Buscemi, A., Guarino, S., Ciulla, G., \& Lo Brano, V. (2021). A methodology for optimisation of solar dish-Stirling systems size, based on the local frequency distribution of direct normal irradiance. Applied Energy, 303, 117681. 
[37] Schiel W, Schweiber A, Stine WB. Evaluation of the 9-kw e dish/stirling system of schlaich bergermann und partner using the proposed iea dish/stirling performance analysis guidelines. Intersoc. Energy Convers. Eng. Conf. 1994, 1994.

[38] Badescu V. Modeling solar radiation at the earth's surface. vol. 1. Springer; 2014.

[39] Stine W. DR. A Compendium of Solar Dish/Stirling Technology. Sandia Natl Lab 1994:SAND 93-7026.

[40] Law EW, Kay M, Taylor RA. Evaluating the benefits of using short-term direct normal irradiance forecasts to operate a concentrated solar thermal plant. Sol Energy 2016;140:93108. https://doi.org/https://doi.org/10.1016/j.solener.2016.10.037.

[41] Gueymard CA, Ruiz-Arias JA. Extensive worldwide validation and climate sensitivity analysis of direct irradiance predictions from 1-min global irradiance. Sol Energy 2016;128:1-30. https://doi.org/https://doi.org/10.1016/j.solener.2015.10.010.

[42] Vignola F, Harlan P, Perez R, Kmiecik M. Analysis of satellite derived beam and global solar radiation data. Sol Energy 2007;81:768-72. https://doi.org/10.1016/j.solener.2006.10.003.

[43] Larrañeta M, Moreno-Tejera S, Lillo-Bravo I, Silva-Pérez MA. A methodology for the stochastic generation of hourly synthetic direct normal irradiation time series. Theor Appl Climatol 2018;131:1517-27. https://doi.org/10.1007/s00704-017-2188-4.

[44] Ahmadi MH. Investigation of Solar Collector Design Parameters Effect onto Solar Stirling Engine Efficiency. J Appl Mech Eng 2012;01:10-3. https://doi.org/10.4172/21689873.1000102.

[45] Roesch A, Wild M, Ohmura A, Dutton EG, Long CN, Zhang T. Assessment of BSRN radiation records for the computation of monthly means. Atmos Meas Tech 2011;4:339-54.

[46] Meteonorm. Meteonorm global meteorological database--Handbook Part II: Theory, Version 7.1.7.215172015.

[47] Suri M, Huld T, Dunlop ED, Cebecauer T. Geographic aspects of photovoltaics in Europe: contribution of the PVGIS website. IEEE J Sel Top Appl Earth Obs Remote Sens 2008;1:3441.

[48] Remund J. Quality of meteonorm version 6.0. Europe 2008;6:389.

[49] Amillo AG, Huld T, Müller R. A new database of global and direct solar radiation using the eastern meteosat satellite, models and validation. Remote Sens 2014;6:8165-89. https://doi.org/10.3390/rs6098165.

Preprint version; Please cite this paper as: Buscemi, A., Guarino, S., Ciulla, G., \& Lo Brano, V. (2021). A methodology for optimisation of solar dish-Stirling systems size, based on the local frequency distribution of direct normal irradiance. Applied Energy, 303, 117681. 
[50] Psiloglou BE, Kambezidis HD, Kaskaoutis DG, Karagiannis D, Polo JM. Comparison between MRM simulations, CAMS and PVGIS databases with measured solar radiation components at the Methoni station, Greece. Renew Energy 2020;146:1372-91. https://doi.org/10.1016/j.renene.2019.07.064.

[51] Baker E, Fowlie M, Lemoine D, Reynolds SS. The Economics of Solar Electricity. Annu Rev Resour Econ 2013;5:387-426. https://doi.org/10.1146/annurev-resource-091912151843.

[52] D. M. 16 Febbraio 2016. Incentivazione della produzione di energia termica da impianti a fonti rinnovabili ed interventi di efficienza energetica di piccole dimensioni 2016:65-71.

[53] D. M. 28 luglio 2005. “Criteri per l'incentivazione della produzione di energia elettrica mediante conversione fotovoltaica della fonte solare." 2005.

Preprint version; Please cite this paper as: Buscemi, A., Guarino, S., Ciulla, G., \& Lo Brano, V. (2021). A methodology for optimisation of solar dish-Stirling systems size, based on the local frequency distribution of direct normal irradiance. Applied Energy, 303, 117681. 